\title{
The Role of Mesenchymal Stem Cells in the Tumor Microenvironment
}

\author{
Aline M. Betancourt and Ruth S. Waterman \\ Tulane University School of Medicine and Ochsner Clinic Foundation, \\ New Orleans, Louisiana, \\ USA
}

\section{Introduction}

Currently, there are many promising clinical trials using mesenchymal stem cells (MSCs) in cell-based therapies of diseases ranging widely from graft-versus-host to joint and cartilage disorders (Salem and Thiemermann 2010; Tolar, Le Blanc et al.). Increasingly, however, there is a concern over the clinical use of MSCs because they are also known to home to tumors and once resident in the tumor microenvironment (TME) to support tumor growth and spread (Karnoub, Dash et al. 2007; Kidd, Spaeth et al. 2008; Coffelt, Marini et al. 2009; Klopp, Gupta et al. 2010; Klopp, Gupta et al. 2011). Conversely, other studies have reported that MSCs found in the TME diminish tumor growth, which has further generated some controversy in this field (reviewed in (Klopp, Gupta et al. 2010; Klopp, Gupta et al. 2011). Either way as a result of the MSC propensity for the TME, genetically modified MSCs that can act as "Trojan horses" and deliver anti-cancer therapeutics into the tumor stroma are being evaluated as a promising new specific cell-based therapy for cancer.

Our group established that MSCs in the ovarian tumor microenvironment promoted tumor growth and favored angiogenesis (Zwezdaryk, Coffelt et al. 2007; Coffelt and Scandurro 2008; Coffelt, Marini et al. 2009). We also developed new methodology to induce the conventional mixed pool of MSCs into two uniform but distinct phenotypes, MSC1 and MSC2 (Waterman, Tomchuck et al. 2010). We based their classification on several parallel observations reported within the monocyte literature. Like MSCs, heterogeneous bone marrow-derived monocytes respond to stress or "danger" inflammatory signals and home to tissue injury. Monocyte polarization into pro-inflammatory macrophages (M1) occurs early on in tissue repair whereas, monocyte polarization into anti-inflammatory macrophages (M2) follows later to help in tissue injury resolution (Mantovani, Sozzani et al. 2002; Martinez, Gordon et al. 2006). Although, this is a much simplified view of what occurs in the complex process of wound healing and repair, it provides a convenient paradigm to begin to dissect critical components within this biological process (Mantovani, Sica et al. 2007; Mosser and Edwards 2008; Mosser and Zhang 2008). Likewise, we believe that proinflammatory MSC1 and anti-inflammatory MSC2 provide convenient tools with which to begin to interrogate the role of MSCs in the tumor microenvironment.

In recent studies we found that MSC2 supported ovarian cancer growth and spread while surprisingly MSC1 had an opposite anti-tumor effect (Waterman 2011). We suggest that by 
more closely studying the distinct tumor effects observed for these MSC phenotypes we may figure out why in the studies mentioned above MSCs favor tumor growth while in others MSCs attenuate tumors. In other words, induction into each discrete but uniform phenotype may help resolve some of the controversies surrounding the use of MSCs in cell based-therapies.

It is known that MSCs resident in the TME contribute mitogens, extracellular matrix proteins, angiogenic, and inflammatory factors. These contributions are not trivial to tumor growth and spread and serve to recruit specific subsets of leukocytes and endothelia to the TME that profoundly influence tumors. MSC1 in the TME are expected to attenuate tumor growth by secretion of anti-tumor factors and recruitment of anti-tumor immunity. MSC2 found in TME should promote tumor growth and spread by secretion of mitogens and supressing anti-tumor immune responses. We expect that by identifying the differences between these two phenotypes we will shed some light on the growing controversy on the role of MSCs in tumors, and provide a means to safely deliver MSCs in cell-based therapies. We have attempted to provide all relevant information that is available concerning these issues in the sections included in this chapter.

\section{Current understanding of MSCs function in the TME}

Mesenchymal stem cells (MSCs) are a group of heterogeneous multipotent cells that can be easily isolated from many tissues throughout the body. Though initially isolated from the bone marrow, they are now recognized to be mostly in perivascular regions throughout the body (Feng, Mantesso et al. ; Zwezdaryk, Coffelt et al. 2007; da Silva Meirelles, Caplan et al. 2008). The discovery of these cells dates back to the 1960s (Friedenstein, Piatetzky et al. 1966). In recent years, MSCs have been widely studied due to their ability to be expanded in culture and stored without losing their capacity to differentiate into many different cells of mesodermal origin such as osteoblasts, chondrocytes, and adipocytes (Bruder, Jaiswal et al. 1997; Jaiswal, Haynesworth et al. 1997; Digirolamo, Stokes et al. 1999; Phinney, Kopen et al. 1999; Pittenger, Mackay et al. 1999). MSCs can also transdifferentiate into cells of ectodermal (Kopen, Prockop et al. 1999) and endodermal (Sun, Chen et al. 2007; Ju, Teng et al. 2010) origins. As a result, many preclinical studies have focused on evaluating the capacity of MSCs to repair and replace injured or diseased tissues of all origins.

Despite these research efforts however, there is growing evidence that the clinical benefit of MSCs in cell-based therapies is not the replacement of the injured tissue, but rather their efficiency in modulating aberrant host immune responses (Pittenger, Mackay et al. 1999; Prockop 2003; Prockop 2009). Following the remarkable clinical observations by the Le Blanc group who used the successful delivery of MSCs as a last resort to stave off graft-versushost disease in a young boy, the immune modulating capability of MSCs is now more widely recognized (Le Blanc, Rasmusson et al. 2004). Further evidence indicating that immunomodulation is the primary activity of MSCs can be gleaned from the observation in many studies that although infused MSCs home to sites of injury and provide treatment benefit in widely ranging diseases, they can rarely be detected within the repaired tissue. Subsequent research efforts are beginning to identify the myriad ways that MSCs affect host immune responses. These appear to be mediated both by direct cell-to-cell contact and indirectly by the secretion of inflammatory factors (further discussed below) (Aggarwal and Pittenger 2005; Abdi, Fiorina et al. 2008; Uccelli, Moretta et al. 2008; Nemeth, Mayer et al. 2009; Bunnell, Betancourt et al. 2010; Singer and Caplan 2011). 
Thus far, the immune modulating effects of MSCs include inhibition of the proliferation of activated CD8+ and CD4+ T lymphocytes and natural killer (NK) cells, recruitment and support of regulatory $\mathrm{T}$ cells, suppression of Th17 lymphocytes and immunoglobulin production by plasma cells, inhibition of maturation of dendritic cells (DCs), as well as attenuation of mast cells (Aggarwal and Pittenger 2005; Abdi, Fiorina et al. 2008; Uccelli, Moretta et al. 2008; Nemeth, Mayer et al. 2009; Nemeth, Keane-Myers et al. 2010). MSCs secrete various inflammatory factors including TNF-a-induced protein 6 (TNAIP6 or TSG6), prostaglandin E2 (PGE2), human leukocyte antigen G5 (HLA-G5), hepatocyte growth factor (HGF), inducible nitric oxide synthase (iNOS), indoleamine-2,3-dioxygenase (IDO), transforming growth factor $\beta$ (TGF- $\beta$ ), leukemia-inhibitory factor (LIF), and interleukin (IL)10 (Krampera, Pasini et al. 2006; Gur-Wahnon, Borovsky et al. 2009; Bunnell, Betancourt et al. 2010; Singer and Caplan 2011).

MSCs express low levels of human leukocyte antigen (HLA) major histocompatibility complex (MHC) class I, do not express co-stimulatory molecules (B7-1/CD80 and -2/CD86, CD40, or CD40L), and must be induced to express MHC class II and Fas ligand that likely allows the safe delivery of these cells in non-self (allogeneic) hosts (Aggarwal and Pittenger 2005; Bunnell, Betancourt et al. 2010). Indeed, MSCs stand alone among the other types of stem cells such as embryonic or induced pluripotent (iPS) cells being considered in regenerative medicine for their safe, non-immune provoking, allogeneic host delivery capability. This has prompted many new and established businesses to amass expanded stockpiles of MSCs ready for use in the treatment of many human diseases including cancer (Salem and Thiemermann 2010).

Given the ability to deliver expanded, stockpiled clinical grade MSCs, knowing that they specifically home to the TME, and that they secrete mitogens, extracellular matrix proteins, angiogenic and inflammatory factors, it is not hard to conceive that MSCs might on the one hand influence tumors, and on the other hand, be used as vehicles to deliver anti-cancer agents. At issue is that despite intense study over the past few years, the effect of MSCs on tumors or their function in the TME is far from clear. Some studies report that MSCs promote tumor growth and spread while others report that MSCs attenuate tumor growth (Table 1). The distinct effects by MSCs on tumors has recently been attributed to differences in the experimental cancer model, the heterogeneity of MSC preparations, the dose or timing of the delivered MSCs, the animal host, or some as yet unknown factor (Klopp, Gupta et al. 2010; Klopp, Gupta et al. 2011). Also at play may be that the primary immunomodulatory function of MSCs is not realized in the context of most of these studies, which rely on immune compromised animal models. It is clear however, that with all of their unique properties MSCs make attractive candidates in cell therapies of cancer. In fact, a few promising pre-clinical reports have shown the delivery by MSCs of several anti-cancer therapeutics such as interferon (IFN)- $\beta$, cytosine deaminase, tumor necrosis factor-related apoptosis-inducing ligand (TRAIL), and oncolytic viruses to tumors (Pittenger, Mackay et al. 1999; Studeny, Marini et al. 2002; Prockop 2003; Studeny, Marini et al. 2004; Nakamizo, Marini et al. 2005; Ren, Li et al. 2007; Kim, Lim et al. 2008; Ren, Kumar et al. 2008; Ren, Kumar et al. 2008; Mader, Maeyama et al. 2009; Prockop 2009). Though it would seem from these reports that any pro-tumor MSC effect is outweighed by the anti-cancer strategy, it is important to fully understand all of the contributions that MSCs have in the TME of immune competent tumors to safely use them in cell-based therapies of human disease.

It is appreciated that MSCs contribute in a number of ways within the TME. As mentioned above, it has long been documented that MSCs elaborate a number of factors directly, after 
stimulation, or after contact with adjacent cells. These include mitogens, extracellular matrix (ECM) proteins, angiogenic factors, and inflammatory factors, all of which could potentially influence tumor growth and spread. These are summarized below along with some of the pro-tumorigenic and anti-tumorigenic evidence for MSCs.

\subsection{Pro-tumorigenic evidence}

There are a growing number of studies implicating a role for MSCs derived from various tissues in tumor growth and spread. Upon review of these studies and the anti-tumorigenic

\begin{tabular}{|c|c|c|c|c|c|}
\hline Study & $\begin{array}{c}\text { MSC } \\
\text { Source }\end{array}$ & $\begin{array}{c}\text { MSC:Tumor } \\
\text { Ratio }\end{array}$ & $\begin{array}{c}\text { Immune } \\
\text { Status of } \\
\text { animal model }\end{array}$ & $\begin{array}{l}\text { Tumor } \\
\text { Model }\end{array}$ & MSC Effect \\
\hline \begin{tabular}{|l|} 
(Muehlberg, \\
Song et al. 2009)
\end{tabular} & $\begin{array}{l}\mathrm{Hu}, \mathrm{Mu} \\
\text { ASCs }\end{array}$ & $10: 1$ & - & $\mathrm{Br}$ & $\begin{array}{l}\text { Larger tumor, } \\
\text { increased SDF-1 }\end{array}$ \\
\hline $\begin{array}{l}\text { (Karnoub, Dash } \\
\text { et al. 2007) }\end{array}$ & $\mathrm{Hu}$ BMSCs & $3: 1$ & - & $\mathrm{Br}$ & $\begin{array}{l}\text { Larger tumor, } \\
\text { increased spread, } \\
\text { CCL5-mediated }\end{array}$ \\
\hline $\begin{array}{l}\text { Galie, } \\
\text { Konstantinidou } \\
\text { et al. 2008) }\end{array}$ & $\mathrm{Mu}$ ASCs & $1: 1$ & + & $\mathrm{Br}$ & $\begin{array}{l}\text { Larger tumors, } \\
\text { pro-angiogenesis }\end{array}$ \\
\hline $\begin{array}{l}\text { (Yu, Ren et al. } \\
2008)\end{array}$ & $\mathrm{Hu}$ ASCs & $1: 1,1: 2,1: 10$ & - & Lu, Glioma & $\begin{array}{l}\text { Larger tumor, } \\
\text { anti-apoptosis }\end{array}$ \\
\hline $\begin{array}{l}\text { (Djouad, Plence } \\
\text { et al. 2003; } \\
\text { Djouad, Fritz et } \\
\text { al. 2005) }\end{array}$ & $\mathrm{Mu}$ BMSCs & $1: 1$ & + & Melanoma & $\begin{array}{l}\text { Larger tumors, } \\
\text { inflammation }\end{array}$ \\
\hline $\begin{array}{l}(\text { Kucerova, } \\
\text { Matuskova et al. })\end{array}$ & $\mathrm{Hu}$ ASCs & 1:5-1:10 & - & $\begin{array}{c}\text { Melanoma } \\
\text { Glioblastoma }\end{array}$ & $\begin{array}{l}\text { Larger tumors, } \\
\text { VEGF and SDF1- } \\
\text { CXCR4 }\end{array}$ \\
\hline $\begin{array}{l}\text { (Coffelt, Marini } \\
\text { et al. 2009) }\end{array}$ & $\mathrm{Hu}$ BMSCs & $1: 10$ & - & Ova & $\begin{array}{l}\text { Larger tumors, } \\
\text { pro-angiogenesis }\end{array}$ \\
\hline $\begin{array}{l}\text { (Lin, Yang et al. } \\
2010)\end{array}$ & $\mathrm{Hu}$ ASCs & $1: 2$ & - & $\operatorname{Pr}$ & $\begin{array}{l}\text { Larger tumors, } \\
\text { pro-angiogenesis } \\
\text { and CXCR4 }\end{array}$ \\
\hline \begin{tabular}{|l|} 
(Prantl, \\
Muehlberg et al.)
\end{tabular} & $\mathrm{Hu}$ ASCs & 1:10 & - & $\operatorname{Pr}$ & $\begin{array}{l}\text { Larger tumors, } \\
\text { pro-angiogenesis }\end{array}$ \\
\hline $\begin{array}{l}\text { (Zhu, Xu et al. } \\
\text { 2006) }\end{array}$ & $\mathrm{Hu}$ BMSCs & $10: 1,1: 1$ & - & $\mathrm{Co}$ & $\begin{array}{l}\text { Larger tumors, } \\
\text { pro-angiogenesis }\end{array}$ \\
\hline $\begin{array}{l}\text { (Shinagawa, } \\
\text { Kitadai et al.) }\end{array}$ & $\mathrm{Hu}$ BMSCs & $1: 2$ & - & Co & $\begin{array}{l}\text { Larger tumors, } \\
\text { anti-apoptosis }\end{array}$ \\
\hline
\end{tabular}

Abbreviations: Hu- human, Mu- murine, ASC- adipose-derived MSCs, BMSCs- bone marrow-derived MSCs, Immune Status of animal model- - immune compromised +- immune competent, Br- breast, Lulung, Ov- ovarian, Pr- prostate, and Co- colon cancer cell lines.

Table 1. Pro-tumorigenic evidence for MSCs in the TME. 
ones below it is tempting to speculate that cancers of endo- and ectodermal tissue origin are likely supported by MSCs whereas cancers of mesodermal tissue origin are likely inhibited by MSCs. However, as stated above, the fact that most of the studies are for technical reasons conducted in immune compromised animals greatly limits these conclusions and our understanding of the final outcome of MSCs in cancer. Evidence that MSCs promote tumor growth and their stated mechanism(s) is given by the studies summarized in Table 1 . MSCs supported growth of breast, brain, lung, ovary, prostate, and colon, as well as lymphoma and melanoma (Kucerova, Matuskova et al. ; Shinagawa, Kitadai et al. ; Djouad, Plence et al. 2003; Djouad, Fritz et al. 2005; Zhu, Xu et al. 2006; Karnoub, Dash et al. 2007; Galie, Konstantinidou et al. 2008; Yu, Ren et al. 2008; Coffelt, Marini et al. 2009; Muehlberg, Song et al. 2009; Lin, Yang et al. 2010). The MSCs delivered at high ratios to the experimental tumor cell lines most commonly promoted tumor growth and metastasis. Most studies reported an increase in angiogenesis as a result of increased VEGF production by the MSCs in the TME. Some studies reported attenuation of tumor apoptosis. Chemokines such as Chemokine Ligand-5 (CCL5 or RANTES) and stromal-derived factor-1 (SDF-1)-C-X-C chemokine receptor-4 (CXCR4) axis effects by the MSCs were associated with elevated tumor migration and spread.

The secretion of pro-angiogenic molecules by the MSCs likely assist the tumors in capturing essential nutrients - perhaps also explaining the anti-apoptosis effects-- and in gaining the ability to spread to remote tissues - explaining the role of the chemokines. MSCs are known to secrete pro-angiogenic factors such as VEGF and possibly erythropoietin (Epo) thus this chief effect is not unexpected (Zwezdaryk, Coffelt et al. 2007; Singer and Caplan 2011). More studies are needed that focus on whether MSC conditioned medium is sufficient to elicit these responses and to test whether cell-to-cell contact by the MSCs, leukocytes, and/or cancer cells is required for the promotion of tumor growth and spread by MSCs.

\subsection{Anti-tumorigenic evidence}

While the pro-tumorigenic activity of MSCs is largely characterized by the secretion of proangiogenic molecules, the anti-tumorigenic activity of these cells is exemplified by modulation of members of the Wnt-signaling family (Table 2). MSCs inhibited the growth of tumors in several different models (Maestroni, Hertens et al. 1999; Ohlsson, Varas et al. 2003; Khakoo, Pati et al. 2006; Lu, Yuan et al. 2008; Qiao, Xu et al. 2008; Qiao, Xu et al. 2008; Cousin, Ravet et al. 2009; Otsu, Das et al. 2009; Zhu, Sun et al. 2009; Dasari, Kaur et al. ; Dasari, Velpula et al. ; Secchiero, Zorzet et al.). For instance, in studies that used fetal tissue derived MSCs, their secretion of the Wnt-signalling inhibitor Dickkopf-related protein-1 (DKK-1) inhibited breast and liver cancer cell lines (Qiao, Xu et al. 2008; Qiao, Xu et al. 2008). When the researchers used a neutralizing antibody or small interfering RNA to block DKK-1 within MSCs, the inhibitory tumor effects were attenuated. In the DKK-1 associated inhibition of primary leukemia by adipose-derived MSCs (ASCs), the stem cell transcription factor NANOG was also implicated (Zhu, Sun et al. 2009).

Interestingly, in an immune competent model, MSCs typically believed to be immune suppressive, recruited leukocytes and appeared to favor pro-inflammatory monocyte/granulocyte infiltration, which promoted rat colon carcinoma growth (Ohlsson, Varas et al. 2003). In the other immune competent model studies, one reported lack of immune suppression or attenuation of T-cell activation by the admixed MSCs but did not report the changes in any other pro-inflammatory leukocytes, and the other study was 
focused more on the effect on angiogenesis by the MSCs rather than on inflammatory cells (Lu, Yuan et al. 2008; Otsu, Das et al. 2009).

\begin{tabular}{|c|c|c|c|c|c|}
\hline Study & MSC Source & $\begin{array}{l}\text { MSC:Tumor } \\
\text { Ratio }\end{array}$ & $\begin{array}{c}\text { Immune } \\
\text { Status of } \\
\text { animal model } \\
\end{array}$ & $\begin{array}{l}\text { Tumor } \\
\text { Model }\end{array}$ & MSC Effect \\
\hline $\begin{array}{l}\text { (Khakoo, Pati } \\
\text { et al. 2006) }\end{array}$ & $\mathrm{Hu}$ BMSCs & $1: 1,2: 1$ & - & $\begin{array}{l}\text { Kaposi's } \\
\text { Sarcoma }\end{array}$ & $\begin{array}{l}\text { Smaller tumors, E- } \\
\text { cadherin } \\
\text { dependent AKT- } \\
\text { inhibition }\end{array}$ \\
\hline $\begin{array}{l}\text { (Secchiero, } \\
\text { Zorzet et al.) }\end{array}$ & $\mathrm{Hu}$ BMSCs & $1: 2,1: 10$ & - & $\begin{array}{c}\mathrm{NH}- \\
\text { Lymphoma }\end{array}$ & $\begin{array}{l}\text { Smaller tumors, } \\
\text { increased animal } \\
\text { survival }\end{array}$ \\
\hline $\begin{array}{l}\text { (Lu, Yuan et } \\
\text { al. 2008) }\end{array}$ & $\mathrm{Mu}$ BMSCs & $2-4: 1$ & + & $\begin{array}{c}\text { Insulinoma } \\
\mathrm{Li}\end{array}$ & $\begin{array}{l}\text { Decreased ascites, } \\
\text { pro-apoptosis }\end{array}$ \\
\hline $\begin{array}{l}\text { (Zhu, Sun et } \\
\text { al. 2009) }\end{array}$ & $\mathrm{Hu}$ ASCs & $1: 10$ & - & Leukemia & $\begin{array}{l}\text { DKK-1 mediated } \\
\text { anti-proliferation }\end{array}$ \\
\hline $\begin{array}{l}(\text { Cousin, } \\
\text { Ravet et al. } \\
\text { 2009) } \\
\end{array}$ & $\mathrm{Hu}$ ASCs & $\begin{array}{c}10^{3} \mathrm{ASCs} / \mathrm{mm}^{3} \\
\text { tumor }\end{array}$ & - & Pan & Smaller tumors \\
\hline $\begin{array}{l}\text { (Otsu, Das et } \\
\text { al. 2009) }\end{array}$ & $\mathrm{Mu}$ BMSCs & \begin{tabular}{|c|}
$10^{6}$ \\
MSCs $/ 700 \mathrm{~mm}^{3}$ \\
tumor
\end{tabular} & + & Melanoma & $\begin{array}{l}\text { Smaller tumors, } \\
\text { anti-angiogenesis }\end{array}$ \\
\hline \begin{tabular}{|l|} 
(Maestroni, \\
Hertens et al. \\
$1999)$
\end{tabular} & $\mathrm{Hu}$ BMSCs & $1: 1$ & - & $\begin{array}{c}\text { Melanoma, } \\
\text { Lu }\end{array}$ & $\begin{array}{l}\text { Smaller tumors } \\
\text { and mets with } \\
\text { GM-CSF tx MSCs }\end{array}$ \\
\hline \begin{tabular}{|l|} 
(Dasari, Kaur \\
et al. ; Dasari, \\
Velpula et \\
al.)
\end{tabular} & $\mathrm{Hu}$ UCSCs & $1: 4$ & - & Glioma & $\begin{array}{l}\text { Smaller tumors, } \\
\text { 个PTEN, } \\
\downarrow \text { PI3K,AKT }\end{array}$ \\
\hline $\begin{array}{l}\text { (Qiao, Xu et } \\
\text { al. 2008) }\end{array}$ & $\begin{array}{l}\text { Hu MSCs- } \\
\text { TERT tx }\end{array}$ & $1: 100$ & - & $\mathrm{Br}$ & $\begin{array}{l}\text { Smaller tumors, } \\
\text { less mets, DKK-1 } \\
\text { mediated Wnt1 } \\
\text { inhibition }\end{array}$ \\
\hline $\begin{array}{l}\text { (Qiao, Xu et } \\
\text { al. 2008) }\end{array}$ & $\begin{array}{l}\text { Hu MSCs- } \\
\text { TERT tx }\end{array}$ & $1: 1$ & - & $\mathrm{Li}$ & $\begin{array}{l}\text { Smaller tumors, } \\
\text { less mets, DKK-1 } \\
\text { mediated Wnt1 } \\
\text { inhibition }\end{array}$ \\
\hline $\begin{array}{l}\text { Ohlsson, } \\
\text { Varas et al. } \\
2003) \\
\end{array}$ & $\begin{array}{c}\mathrm{Mu} \\
\mathrm{BpMSCs}-c- \\
m y c \\
\end{array}$ & $1: 1-10$ & + & Co & $\begin{array}{l}\text { Smaller tumors, } \\
\text { 个inflammation }\end{array}$ \\
\hline
\end{tabular}

Abbreviations: Hu- human, Mu- murine, ASC- adipose-derived MSCs, BMSCs- bone marrow-derived MSCs, UCSCs- umbilical cord-derived MSCs, MSCs-TERT tx -MSC cell line immortalized with telomerase vectors, BpMSCs-c-myc-bone marrow-derived MSC progenitor cells immortalized with $c$ myc, Immune Status of animal model- - immune compromised +- immune competent, Br- breast, Cocolon, Li- liver, Lu- lung, NH- Non-Hodgkin's lymphoma, and Pan- pancreas cancer cell lines. DKK-1dickkopf-related protein 1, GM-CSF-granulocyte/monocyte-colony stimulating factor, PTENphosphatase and tensin homolog 10, PI3K-phosphoinositol-3-kinase.

Table 2. Anti-tumorigenic evidence for MSCs in the TME. 


\subsection{Controversies}

Greater than a 100 clinical trials are underway or completed that investigate MSC-based therapy of human disease, and thus far the reports of adverse effects related to the therapy have been unremarkable (Salem and Thiemermann 2010; Tolar, Le Blanc et al. 2010; Singer and Caplan 2011). Therapy-related tumorigenicity has not been found, yet the preclinical studies presented above argue that we should carefully study this MSC potential. The question is why did MSCs promote cancer growth and spread in some studies, while in others MSCs diminished growth and spread? To begin to address this question there are a few important issues that have to be considered. First is the fact that surprisingly the chief effect of MSC-based therapies on disease is the modulation of the inflammatory host responses and not the replacement of injured tissue. Secondly, this observed therapeutic benefit is carried out by a few lingering MSCs that survive the relatively quick clearance of the cell bolus from the circulation-given that very small numbers of MSCs are ever detected at the sites of injury (Prockop 2009). Thirdly, it is known that both the adaptive and innate immune response arms profoundly influence tumor growth and spread by a complex interplay between inflammation and immunosurveillance (Frese and Tuveson 2007; Cheng, Ramesh et al. 2010). To resolve some of this controversy and to better understand the complex nature of the MSC-tumor interaction these issues need to be taken into account in future studies.

It is difficult to accurately model tumorigenesis with human tumor xenograft models in immunodeficient mice to finally resolve the effect that MSC-based therapy will have on cancer (Frese and Tuveson 2007; Cheng, Ramesh et al. 2010). Moreover, the number of MSCs interacting with the tumor must reflect more closely what is observed by the clinical experience. To more precisely model tumorigenicity attempts have been made at humanizing the murine immune system by eliminating the endogenous immune system followed by engraftment of human bone marrow or immune cells (Frese and Tuveson 2007). The problem with this approach has been that species-specific differences in both arms of the immune system confound interpretations. Immunocompetent autochthonous mouse models of human cancer provide a valuable tool that better addresses some of these issues. Though far from perfect, these models more closely parallel human carcinogenesis by allowing intrinsic tumor formation with immune surveillance and offer a better alternative system to study MSC-tumor interactions.

Apart from the limitations of current cancer models there are many other reasons that have been suggested to explain the divergent effects of MSCs in tumors (Klopp, Gupta et al. 2010; Klopp, Gupta et al. 2011). These include the heterogeneity of cells present in current MSC preparation protocols. Convention dictates that more homogeneous preparations of MSCs will also yield more consistent therapeutic outcomes with these cells. However, provided that we can overcome this hurdle and deliver more uniform cells, we may never get away from the variability that comes from the human donors. The age, gender, weight, and disease status of the donor may always affect efficacy outcomes and needs to be investigated more closely. Differences in the tissue source of the MSCs, whether bone marrow, adipose, umbilical cord, or other, also appear to affect a number of MSC functions (Sakaguchi, Sekiya et al. 2005; Hass, Kasper et al. 2011). Further complicating matters in all MSC-based therapy is the cell number and dosing frequency used to achieve a particular therapeutic efficacy. Cancer is a complex disease and to fully understand the contribution of MSCs, which are also intricate, more careful consideration of all these issues needs to be given. Despite these hurdles, MSCs remain an intriguing vehicle that can specifically target tumors. 


\section{Contributions by MSCs to tumors}

In spite of all the limitations described, there is agreement about certain factors that MSCs elaborate that are important to tumorigenesis. It has long been know that MSCs synthesize a broad spectrum of growth factors, extracellular matrix proteins (ECM), cytokines, chemokines, and angiogenic molecules that have effects on cells in their vicinity. The effects of the bioactive molecules that MSCs secrete can be either direct, indirect, or even both: direct by causing intracellular signaling or indirect by causing another cell in the vicinity to secrete a bioactive factor. The indirect activity is typically termed "trophic", based on the original use of this word in neurobiology to distinguish neurotransmitters from other bioactive molecules released from nerve terminals (Caplan and Dennis 2006; Meirelles Lda, Fontes et al. 2009; Singer and Caplan 2011).

Typically, the bioactive molecules that are released from MSCs are reported to be relatively constant between different donors, regardless of age or health status of the donor. However, there can be some donor-specific differences in the levels of the secreted molecules-- that can be as high as a ten-fold difference. Moreover, the specific bioactive agents secreted by individual MSCs are also controlled by their functional status, level of differentiation, and the influence of their local microenvironments (Phinney, Kopen et al. 1999; Djouad, Fritz et al. 2005; Caplan and Dennis 2006; Krampera, Pasini et al. 2006; Tomchuck, Zwezdaryk et al. 2008; Nemeth, Mayer et al. 2009; Prasanna, Gopalakrishnan et al. ; Singer and Caplan 2011). It is expected that MSCs, as multipotent stem cells, will elaborate different levels and arrays of bioactive molecules as they differentiate into defined lineages. Additionally, the pattern and quantity of these secreted factors is well known to feed back on the MSC itself and change both its functional status and physiology.

These MSC paracrine and autocrine factors can have profound effects on local cellular dynamics. For instance, the marrow stroma derived from MSCs not only provides the matrix that supports cell anchorage, but also helps to maintain nearby endothelia and hematopoietic cells. In stroma poor niches within the marrow the hematopoetic stem cells (HSCs) will begin distinct programs of differentiation. The interdependence of MSCs and HSCs in the marrow is governed by the secretion of bioactive molecules such as the stromalderived factor-1 (SDF1) to C-X-C chemokine receptor-4 (CXCR4) axis that helps support full hematopoietic lineage progression (Lopez Ponte, Marais et al. 2007).

\subsection{Soluble, Extracellular Matrix (ECM), and angiogenic factors}

The secretion of these broad range bioactive molecules is now believed to be the main mechanism by which MSCs achieve their therapeutic effect and that likely most affect the tumor microenvironment. These are typically divided by the processes they affect, such as mitogenic, angiogenic, apoptotic, or inflammatory/immune modulating (Table 3). We have added exosomes as a new category to these bioactive factors. Exosomes appear to be a previously unrecognized secretory vesicle that can affect neighboring cells. We include mitogens, Extracellular Matrix (ECM) proteins, and angiogens, exosomes and inflammatory/immune modulating bioactive factors as molecules potentially contributed by MSCs but caution that this is not an exhaustive list of all MSC products. Some of the molecules overlap in function, some of the molecules play greater roles in one species versus another (e.g.-mouse vs. human), and some of the molecules are released only following 
specific stimulation or activation (Tomchuck, Zwezdaryk et al. 2008; Klopp, Gupta et al. 2010; Waterman, Tomchuck et al. 2010; Klopp, Gupta et al. 2011). These have been recently reviewed (da Silva Meirelles, Caplan et al. 2008; Klopp, Gupta et al. 2010; Klopp, Gupta et al. 2011; Singer and Caplan 2011).

\begin{tabular}{|c|c|c|}
\hline Molecule Types & Molecules & Study \\
\hline Mitogens & $\begin{array}{c}\text { bFGF, G-CSF, GM-CSF, HGF, } \\
\text { IGF-I, IL6, Leptin, LIF, SCF, } \\
\text { SDF-1, stanniocalcin-1, TGF } \beta \text {, } \\
\text { VEGF }\end{array}$ & $\begin{array}{l}\text { (Zwezdaryk, Coffelt et al. 2007; Block, } \\
\text { Ohkouchi et al. 2009; Meirelles Lda, Fontes } \\
\text { et al. 2009[Tomchuck, } 2008 \text { \#621; Klopp, } \\
\text { Gupta et al. 2010; Waterman, Tomchuck et } \\
\text { al. 2010; Klopp, Gupta et al. 2011) }\end{array}$ \\
\hline $\begin{array}{l}\text { Extracellular } \\
\text { Matrix Proteins }\end{array}$ & $\begin{array}{l}\text { Collagens, Fibronectin, } \\
\text { Laminin }\end{array}$ & $\begin{array}{l}\text { (Zuckerman and Wicha 1983; Hashimoto, } \\
\text { Kariya et al. 2006; Zwezdaryk, Coffelt et } \\
\text { al. 2007; Tomchuck, Zwezdaryk et al. } \\
\text { 2008; Meirelles Lda, Fontes et al. 2009; } \\
\text { Waterman, Tomchuck et al. 2010) }\end{array}$ \\
\hline Angiogens & $\begin{array}{l}\text { Angiopoetin-1, bFGF, IL6, } \\
\text { IL8, Leptin, stanniocalcin-1, } \\
\text { VEGF }\end{array}$ & $\begin{array}{l}\text { (Zwezdaryk, Coffelt et al. 2007; } \\
\text { Tomchuck, Zwezdaryk et al. 2008; } \\
\text { Meirelles Lda, Fontes et al. 2009; } \\
\text { Waterman, Tomchuck et al. 2010) }\end{array}$ \\
\hline Exosomes & $\begin{array}{c}\text { Pro-inflammatory molecules, } \\
\text { miRNAs }\end{array}$ & $\begin{array}{l}\text { (Anand 2010; Chen, Lai et al. 2010; Lai, } \\
\text { Arslan et al. 2010) }\end{array}$ \\
\hline $\begin{array}{l}\text { Inflammatory/ } \\
\text { Immune } \\
\text { Modulating }\end{array}$ & $\begin{array}{c}\text { galectin-3, galectin-1, HGF, } \\
\text { HLA-G, IDO, IL1 } \beta \text {, IL1RA, } \\
\text { IL6, IL8, IL12, iNOS, IP-10, } \\
\text { LIF, MCP-1, MIP-1, PGE2, } \\
\text { semaphorin-3A, RANTES, } \\
\text { SDF-1, stanniocalcin-1, } \\
\text { TGF } \beta \text {, TSG-6 }\end{array}$ & $\begin{array}{l}\text { (Zwezdaryk, Coffelt et al. 2007; Tomchuck, } \\
\text { Zwezdaryk et al. 2008; Block, Ohkouchi et } \\
\text { al. 2009; Meirelles Lda, Fontes et al. 2009; } \\
\text { Bartosh, Ylostalo et al. 2010; Bunnell, } \\
\text { Betancourt et al. 2010; Klopp, Gupta et al. } \\
\text { 2010; Waterman, Tomchuck et al. 2010; } \\
\text { Danchuk, Ylostalo et al. 2011; Klopp, } \\
\text { Gupta et al. 2011) }\end{array}$ \\
\hline
\end{tabular}

Abbreviations: bFGF- basic fibroblast growth factor, CCL- C-C motif chemokine ligand, CXC- C-X-Cmotif chemokine, CXCL-CXC-ligand, G-CSF-granulocyte-colony stimulating factor, GM-CSFgranulocyte-macrophage-colony stimulating factor, HGF-hepatocyte growth factor (scatter factor), HLA-G- human leukocyte antigen-G, IDO- indoleamine 2,3-dioxygenase, IGF-I-insulin-like growth factor-1, IL-interleukin, IL-1RA- interleukin-receptor 1 antagonist, iNOS-inducible nitric oxide synthase, IP-10-interferon-gamma-inducible protein 10 (CXCL10), LIF-leukemia inhibitory factor, MCP-1monocyte chemoatractant protein-1 (CCL2), MIP1-macrophage inflammatory protein-1 (CCL3), PGE2prostaglandin-E2, PIGF-placental-derived growth factor, RANTES- regulated upon activation normal T cell expressed and secreted (CCL5), SCF-stem cell factor, SDF-1-stromal-derived factor-1, TGF $\beta$-transforming growth factor- $\beta$, TSG-6- TNF-alpha stimulated gene/protein 6 , VEGF-vascularderived endothelial growth factor (vascular permeability factor, VPF).

Table 3. Molecules Contributed by MSCs.

\subsection{Exosomes}

A recently described form of intercellular communication that may also be important in MSC-tumor exchanges is exosomes. These are endosome-derived vesicles of about 40-100 $\mathrm{nm}$ that are formed by the involution of endosome membranes resulting in the formation of 
multi-vesicular bodies (MVBs). Following certain physiological conditions, the MVBs fuse with the plasma membrane and release the exosomes into the circulation or tissue microenvironment. Exosomes have a "saucer-shaped" morphology as determined from electron microscopy analyses. Various methods have been developed to enrich for exosomes derived from a number of cell types including antigen-presenting cells (APCs), monocytes, T-lymphocytes, reticulocytes, mast cells, platelets, fibroblasts, tumor cells, and MSCs (Anand 2010; Lai, Arslan et al. 2010; Tan, De La Pena et al. 2010).

Investigators studying the cardioprotective effect of human embryonic stem cell-derived MSC-conditioned medium (CM) on myocardial ischemia/reperfusion injury reasoned based on proteomic analyses that exosomes were responsible for the beneficial effect (Sze, de Kleijn et al. 2007; Lai, Arslan et al. 2010). Their unbiased proteomic profiling of proteins secreted by MSCs revealed an abundance of membrane and cytosolic proteins. This suggested to them that the trophic effects of MSCs were not mediated by soluble growth factors and cytokines alone. Sze et al. proceeded to enrich for particles by size-exclusion fractionation on HPLC. Based on the size and the composition of the particles they figured exosomes were present in the condition medium of MSCs. Moreover they demonstrated that the enriched fraction of exosomes reduced infarct size in a mouse model of myocardial ischemia/reperfusion injury.

The particles could be visualized by electron microscopy and were shown to be phospholipid vesicles consisting of cholesterol, sphingomyelin, and phosphatidylcholine. Moreover, they were composed of known exosome-associated proteins-- CD81, CD9, and Alix. Exosomes are known to have a specific protein composition, including CD9, CD81, Alix, TSP-1, SOD-1, and pyruvate kinase. CD9 and CD81 are tetrapannin membrane proteins that are also localized in the membrane of exosomes. Consistent with the presence of exosomes in the CM of the MSCs this study further demonstrated that CD9 in the CM was a membrane-bound protein while SOD-1 was localized within a lipid vesicle. They eliminated the possibility of immune cells or platelets as sources of exosomes with an ex vivo mouse model of myocardial ischemia/reperfusion injury.

Similarly in human ESC-derived MSC conditioned medium other investigators found exosomes that contained small RNAs (less than $300 \mathrm{nt}$ ) encapsulated in cholesterol-rich phospholipid vesicles. The small RNAs were identified by a number of biochemical and genetic criteria to be microRNAs (miRNAs). Of interest the Let-7 family of miRNAs figured prominently in these studies (Chen, Lai et al. 2010; Koh, Sheng et al. 2010). It is becoming increasingly clear that miRNAs are potent global gene regulators of many diverse cell functions including adaptation to mitogens, low oxygen (hypoxia), and inflammation. Perhaps this might explain why exosomes are potent immune modulators (Anand 2010). Apart from the molecules present inside the lumen of exosomes, it has been suggested that certain exosomal membrane molecules can interact with their surface receptors on the target cells thereby inducing an immunomodulatory response or activating the immune system. Consistent with this notion, exosome release is enhanced following pathologies where immune activation is required. It has been suggested that immunogenic molecules on the exosomal membrane can activate leukocytes. In support of this idea is the fact that exosomes are analogous to inverted endosomes and thus display inflammatory intracellular factors present normally within plasma membrane. Taking advantage of this inflammatory nature 
of exosomes, clinicians are developing cancer vaccines based on loading dendritic cells (DCs) with tumor antigens, expanding the DCs ex vivo, and subsequently isolating their enriched exosomes (Tan, De La Pena et al. 2010). The tumor antigen loaded exosomes are then reintroduced into patients to elicit tumor specific anti-tumor immunity.

Lastly, highlighting the interactions of tumors and MSCs, exosomes derived from tumors appear to drive adipose-derived MSC differentiation toward tumor associated myofibroblasts that can then contribute to tumor growth and spread (Webber, Steadman et al. 2010; Cho, Park et al. 2011; Cho, Park et al. 2011). Interestingly and perhaps providing a mechanism for the Wnt-signaling mediated anti-tumor effect of MSCs mentioned above, $\beta$-catenin was found to be contained within exosomes (Chairoungdua, Smith et al. 2010). Furthermore, exosomal release of $\beta$-catenin antagonized Wnt-signaling in the recipient cell. These studies emphasize the need for more intense investigations that clarify the role of both tumor- and MSC-derived exosomes in tumorigenesis. Besides identifying new components of tumor biology such studies may identify new therapeutic interventional agents.

\subsection{Immune modulation}

Apart from the ability of MSCs to contribute mitogens, ECM proteins, pro-angiogenic molecules, inflammatory agents, and exosomes to the TME, their most significant contribution may be modulating specific subsets of immune cells (Table 4)(Fibbe, Nauta et al. 2007; Nauta and Fibbe 2007; Bunnell, Betancourt et al. 2010; Roddy, Oh et al. 2011; Singer and Caplan 2011; Weiss, Bertoncello et al. 2011). The specific mechanism for this MSC role is not completely understood and may involve direct immune cell-MSC cell contact or indirect effects such as by the contribution of the factors just described or both. However, knowing the importance of immune and inflammatory cells in cancer growth and metastasis, the manner that MSCs in the TME might influence this process deserves closer attention and study.

Though initially described as an ex vivo phenomena requiring the stimulation of the MSCs to lead to suppression of T-lymphocyte activation or proliferation, many clinical trials have asserted immune modulation to be a primary effect of MSC-based therapies (Di Nicola, CarloStella et al. 2002; Krampera, Glennie et al. 2003; Le Blanc, Rasmusson et al. 2004; Aggarwal and Pittenger 2005). In addition, these early observations prompted a number of studies to explore the distinct immune modulatory effects of MSCs derived from a variety of sources and species. Of note, although MSCs influence many immune cells, part of what makes them attractive candidates in cell-based therapies is their muted host immune responses even when delivered into a non-self (allogeneic) host. This is partly due to the fact that MSCs express low levels of human leukocyte antigen (HLA) major histocompatibility complex (MHC) class I, do not express co-stimulatory molecules (B7-1/CD80 and B7-2/CD86, CD40, or CD40L), and express MHC class II and Fas ligand only after specific stimulation.

MSCs are now known to inhibit dendritic cell maturation, $\mathrm{B}$ and $\mathrm{T}$ cell proliferation and differentiation, attenuate natural killer cell and mast cell activity, as well as support the production of suppressive $\mathrm{T}$ regulatory cells (Tregs) while attenuating pro-inflammatory Th17 cells (Table 4) (Najar, Raicevic et al. ; Di Nicola, Carlo-Stella et al. 2002; Krampera, Glennie et al. 2003; Aggarwal and Pittenger 2005; Beyth, Borovsky et al. 2005; Ramasamy, Fazekasova et al. 2007; Ren, Zhang et al. 2008; Uccelli, Moretta et al. 2008; Gur-Wahnon, Borovsky et al. 2009; Meirelles Lda, Fontes et al. 2009; Nemeth, Mayer et al. 2009; Bunnell, Betancourt et al. 2010; Salem and Thiemermann 2010; Tolar, Le Blanc et al. 2010; Brown, Nemeth et al. 2011; Singer and Caplan 2011). 


\begin{tabular}{|c|c|c|}
\hline \begin{tabular}{|c|} 
Immune \\
Response \\
Arm
\end{tabular} & Cells & MSC effects \\
\hline \multirow{4}{*}{ Innate } & Dendritic Cells (APC) & $\begin{array}{l}\text { Inhibition of maturation (CD80/86 expression) by } \\
\text { STAT3 and IL10 (Beyth, Borovsky et al. 2005; Gur- } \\
\text { Wahnon, Borovsky et al. 2009; Mezey, Mayer et al. 2009; } \\
\text { Nemeth, Leelahavanichkul et al. 2009) }\end{array}$ \\
\hline & $\begin{array}{l}\text { Monocyte/Macrophages } \\
\text { (APC) }\end{array}$ & $\begin{array}{l}\text { PGE2 mediated increased IL10 secretion and } \\
\text { attenuation of maturation (Beyth, Borovsky et al. 2005; } \\
\text { Gur-Wahnon, Borovsky et al. 2009; Mezey, Mayer et al. } \\
\text { 2009; Nemeth, Leelahavanichkul et al. 2009) }\end{array}$ \\
\hline & Natural Killer Cells & $\begin{array}{l}\text { Inhibition of proliferation and cytolytic activity } \\
\text { (Giuliani, Oudrhiri et al. 2011) }\end{array}$ \\
\hline & Mast Cells & $\begin{array}{l}\text { COX-2 mediated suppression (Brown, Nemeth et al. } \\
\text { 2011) }\end{array}$ \\
\hline \multirow{5}{*}{ Adaptive } & Th1 & $\begin{array}{l}\text { Inhibition of proliferation/activation (class switching) by } \\
\text { HLA-G5, HGF, iNOS, COX2, IDO, PGE2, TGF } \beta \text { and } \\
\text { indirectly through support of immature APCs reviewed } \\
\text { in (Singer and Caplan 2011) }\end{array}$ \\
\hline & Th2 & $\begin{array}{l}\text { Inhibition of proliferation/activation (class switching) by } \\
\text { HLA-G5, HGF, iNOS, COX2, IDO, PGE2, TGF } \beta \text { and } \\
\text { indirectly through support of immature APCs reviewed } \\
\text { in (Singer and Caplan 2011) }\end{array}$ \\
\hline & Tregs & Recruitent and support (class switching) IL10, TGF $\beta$, LIF \\
\hline & Th17 & $\begin{array}{l}\text { Inhibition of proliferation/activation (class switching) } \\
\text { by COX-2 and PGE2 (Duffy, Pindjakova et al. 2011; } \\
\text { Duffy, Ritter et al. 2011) }\end{array}$ \\
\hline & B lymphocyte & $\begin{array}{l}\text { Suppression of terminal differentiation to plasma cell } \\
\text { (Asari, Itakura et al. 2009) }\end{array}$ \\
\hline
\end{tabular}

Abbreviations: COX-2- cyclooxygenase-2, HGF-hepatocyte growth factor (scatter factor), HLA-Ghuman leukocyte antigen-G, IDO- indoleamine 2,3-dioxygenase, iNOS-inducible nitric oxide synthase, IL10-interleukin-10, LIF-leukemia inhibitory factor, PGE2- prostaglandin-E2, STAT3- signal transducer and activator of transcription-3, TGF $\beta$-transforming growth factor- $\beta$.

Table 4. Immune cells modulated by MSCs.

\subsubsection{MSCs and myelomonocytic cells}

Although the details of the interactions of MSCs with T lymphocytes, B lymphocytes, natural killer cells, and dendritic cells have been investigated in some detail, the effects of MSCs on cells of myelomonocytic lineages (MMCs) observed early on by the Rachmilewitz group remained under investigated until recently (Figure 1. Beyth, Borovsky et al. 2005). The growing clinical evidence for MSCs as major regulators of immune and inflammatory processes and the central role played by MMCs (including monocytes and granulocytes) within them has sparked new interest in studies on the interplay between MSCs and MMCs. Kim and Hematti (2009) reported that human macrophages generated in vitro after co-culture with MSCs assume an immunophenotype defined as IL-10-high, IL-12-low, IL-6-high, and 


\section{Consequences of MSC-Myelomonocytic Cell Interaction}

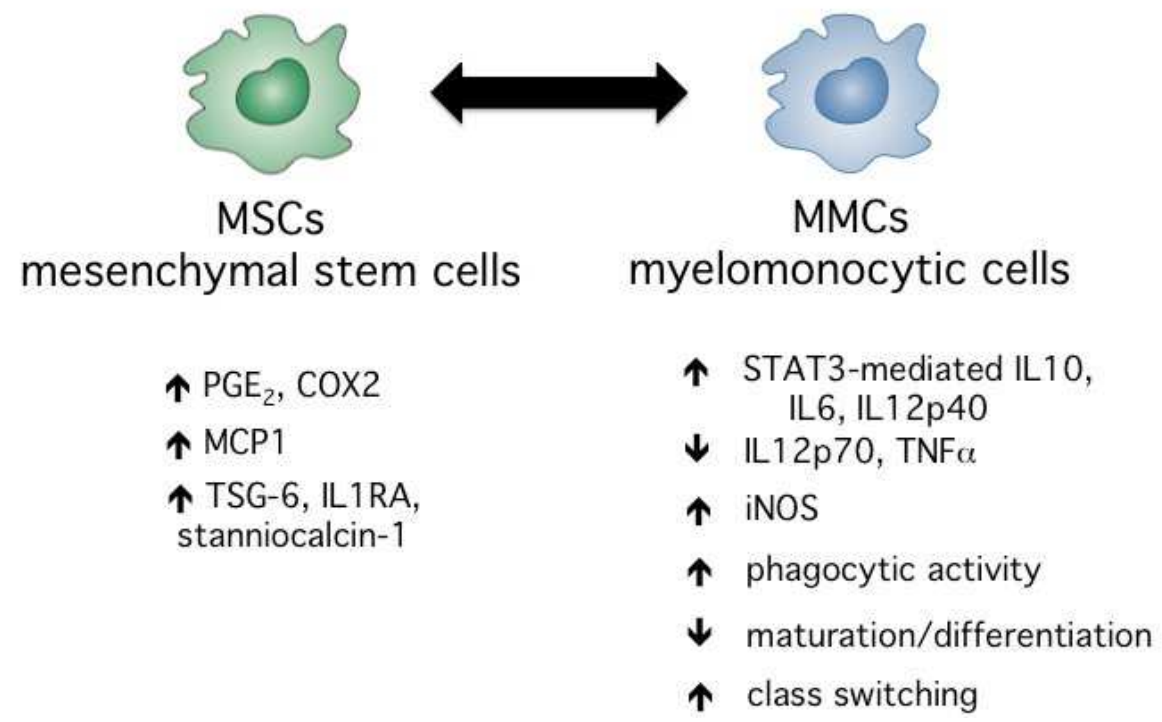

Abbreviations: COX-2- cyclooxygenase-2, IL-interleukin, IL-1RA- interleukin-receptor 1 antagonist, iNOS-inducible nitric oxide synthase, MCP-1-monocyte chemoatractant protein-1 (CCL2), PGE2prostaglandin-E2, STAT3- signal transducer and activator of transcription-3, TSG-6- TNF-alpha stimulated gene/protein.

Fig. 1. The Consequences of the Interaction Between MSCs and Myelomonocytic Cells. Though still in their infancy the studies that have begun to identify the effect of the interactions between MSCs and MMCs whether cell-cell contact dependent or not have so far described those included in the figure. Please refer to the text for details.

TNF-a-low secreting cells (Kim and Hematti 2009). They proposed that these MSC-educated monocytes represent a unique and novel type of alternatively activated macrophage with a potentially significant role in tissue repair. Initially, Beyth et al. reported that human MSCs affect monocytes or dendritic antigen-presenting cell (APC) maturation in a contactdependent manner (Beyth, Borovsky et al. 2005). Later, it was reported that the MSCs cocultured with the APCs induced the expression of the anti-inflammatory IL10 and that activation of the signal transducer and activator of transcription 3 (STAT3) within APCs is linked to abnormal APC differentiation and function by a new contact-dependent mechanism, that plays a critical role in mediating the immunomodulatory effects of MSCs (Gur-Wahnon, Borovsky et al. 2007; Gur-Wahnon, Borovsky et al. 2009). In order to understand this process better, they further extended their studies to tumor cells since tumors secrete a variety of bioactive factors that activate STAT3 within infiltrating APCs. Their studies demonstrated that in at least certain cellular microenvironments, cell-to-cell dependent interactions represent a novel way to activate STAT3 signaling different from the activation of STAT3 seen with soluble bioactive factors. As such this observation suggests an uncoupling of APC activation events and that may consequently independently regulate 
immunity and tolerance. In agreement with these studies, the Mezey group identified other pathways involved in MSC-murine macrophage interactions (Nemeth, Leelahavanichkul et al. 2009). They also showed that LPS-stimulated macrophages produced more IL-10 when cultured with MSCs, but this effect was eliminated if the MSCs lacked the genes encoding TLR4, myeloid differentiation primary response gene-88 (MyD88), TNF-receptor-1 $\alpha$ or cyclooxygenase-2 (COX-2). Their observations demonstrated that MSCs reprogram macrophages by releasing PGE2 that then acts on the macrophages through the prostaglandin EP2 and EP4 receptors. A unique population of MSCs isolated from human gingiva (GMSCs) with similar stem cell-like properties, immunosuppressive, and antiinflammatory functions as bone marrow-derived MSCs were also studied in this context with similar effects (Zhang, Su et al. 2010).

When co-cultured with GMSCs, macrophages acquired an anti-inflammatory M2 phenotype similarly characterized by an increased expression of IL10 and IL6, mannose receptor (MR; CD206), a suppressed production of $\mathrm{TNF} \alpha$, and also decreased the ability to induce Th- 17 cell expansion. Interesting to the discussion on tumors and their microenvironments, they demonstrated that systemically infused GMSCs could home to wounds-- specifically to sites where host macrophages were found-- promoted M2 polarization of the co-localized monocytes, significantly enhanced wound repair, and thus presumably could promote tumor growth by similar mechanisms. In addition, they noted that GMSC treatment suppressed local inflammation by reducing the infiltration of inflammatory cells and the production of IL6 and TNF $\alpha$, and by increased expression of IL10. Another complementary study used muine macrophages stimulated with LPS and co-cultured with MSCs and found the suppression of TNF $\alpha$, IL6, IL12p70 and interferon $\gamma$ but increased levels of secreted IL10 and IL12p40. They noted that the murine MSC effect could be reproduced with MSC conditioned medium suggesting that bioactive factors constitutively released by the murine MSCs may be sufficient for the monocyte effect in this animal species (Maggini, Mirkin et al. 2010). They also found in cell-based therapy of mouse models that MSCs supported macrophages that showed a low expression of CD86 and MHC class II, and with a high ability to secrete IL10 and IL12p40, but not IL12 p70. They suggested in agreement with the other studies, that MSCs switch monocytes into a regulatory profile characterized by enhanced IL10 secretion, reduced inflammatory cytokine elaboration and enhanced phagocytic activity. Apart from elevated IL10 and related signaling mechanisms, other new players in the effects observed for MSCs on monocytes were recently advanced (Block, Ohkouchi et al. 2008; Block, Ohkouchi et al. 2009; Danchuk, Ylostalo et al. 2011; Prockop and Youn Oh 2011)]. Anti-inflammatory effects supported by MSC-monocyte interactions were suggested to also be partly mediated by elevated IL1 receptor antagonist (IL1RA) and by a negative feedback loop in which TNF $\alpha$ and other pro-inflammatory cytokines from resident macrophages activate MSCs to secrete the anti-inflammatory protein TNF $\alpha$ stimulated gene/protein 6 (TSG-6). These reports demonstrate that MSC derived TSG- 6 acts to repress $\mathrm{NF}-\mathrm{KB}$ signaling in the resident macrophages causing attenuation of pro-inflammatory cytokine synthesis. The investigators of these studies also proposed that MSC secreted PGE2 promotes monocytes toward an IL10 secreting phenotype as well as, that anti-inflammatory effects may also be mediated by stanniocalcin-1.

Finally, in another recent report using pre-clinical murine models it was shown that MCP1 secreted by activated MSCs contributes to the bone marrow egress, trafficking, and 
recruitment of monocytes towards remote sites (Shi, Jia et al. 2011). This elegant study demonstrated the intimate and complex cooperation that exists between MSCs and myelomonocytic cells that occurs not only in peripheral tissues or tumors but also in their originating bone marrow niche. It is widely recognized that tumor infiltrating cells can include macrophages, myeloid-derived suppressor cells (MDSCs), MSCs, and TIE2expressing monocytes that are all mostly derived from the bone marrow. MDSCs represent a heterogeneous population of cells of myeloid origin that are expanded and activated in response to growth factors and cytokines released by tumors much like MSCs. The details of the effects of MDSCs on tumors are better understood. It is known that once MDSCs are activated, they accumulate in lymphoid organs and tumors where they exert specific $\mathrm{T}$ cell mediated immune suppression. However, not much is known about whether MDSCs and MSCs cooperate at tumor sites or the nature of that interaction. It is tempting to suggest that MSC-myelomononocytic cell interactions including MSC-MDSC ones represent an intriguing new target for cancer therapies that would break the anti-inflammatory tumor tolerance mechanisms established by these two cell types however, there is still much left to learn before this can come to fruition. Furthermore, while the vast majority of these reports demonstrate the ability of MSCs to suppress immune responses or act in an antiinflammatory manner, there is emerging evidence that supports their contrasting ability to elicit pro-inflammatory responses-- which may also be mediated by their interaction with myelomonocytic cells. Both anti-inflammatory and pro-inflammatory effects will be important to know in dissecting their specific roles in tumors. This information will ultimately help in the design of more effective and targeted cancer therapeutics.

\subsubsection{Immune suppressive or anti-inflammatory responses}

The expression of IDO and iNOS by MSCs has been associated with its immune suppression of T-cell proliferation. Recently, secretion of IDO by MSCs therapeutically delivered in an experimental autoimmune myasthenia gravis model inhibited the proliferation of acetylcholine receptor-specific T cells and B cells and normalized the distribution of Th1, Th2, Th17 and Treg cells (Kong, Sun et al. 2009). IDO catalyzes the conversion of tryptophan, an essential amino acid for T-cell proliferation, into kynurenine. Immune suppression by IDO results from the local accumulation of tryptophan metabolites, rather than through tryptophan depletion (Ryan, Barry et al. 2007). Expression of IDO by MSCs was thought to be IFN- $\gamma$ dependent (Krampera, Cosmi et al. 2006; Ryan, Barry et al. 2007; Bunnell, Betancourt et al. 2010). However, Opitz and colleagues recently demonstrated that IDO expression in MSCs can also be induced by activation of Toll-like receptor 3 (TLR3) and TLR4 via induction of an autocrine IFN- $\beta$ signaling loop involving protein kinase $R$ and independent of IFN-ץ (Opitz, Litzenburger et al. 2009). Interestingly, when MSCs were treated with IFN-ץ in vitro, they expressed extremely high levels of IDO and very low levels of iNOS, whereas mouse MSCs expressed abundant iNOS and very little IDO. These data suggest there is species variation in the mechanisms of MSC immunosuppression (Opitz, Litzenburger et al. 2009).

Prostaglandin E2 (PGE2) is emerging as a central mediator of many of the anti-inflammatory properties of MSCs (Nauta and Fibbe 2007; Uccelli, Moretta et al. 2008). PGE-2 is synthesized from arachidonic acid by cyclooxygenase (COX) enzymes COX-1 and COX-2. 
COX-1 is constitutively expressed in MSCs and COX-2 expression can be induced by inflammatory cytokines such as IL-1 $\beta$, IL-6, IFN- $\gamma$, and TNF- $\alpha$ (Chen, Wang et al. 2010). Inhibitors of PGE2 synthesis attenuated MSC suppression of T cells and natural killer cells (Sotiropoulou, Perez et al. 2006; Chen, Wang et al. 2010). PGE2 is associated also with the MSC-mediated inhibition of dendritic cell maturation. Nemeth et al. reported that activated MSCs released PGE2 causing increased production of IL10 by macrophages, and decreased production of the pro-inflammatory cytokines TNF- $\alpha$ and IL-6 in a murine sepsis model (Sotiropoulou, Perez et al. 2006). Maggini et al. similarly reported macrophage alterations by PGE2 (Maggini, Mirkin et al. 2010).

Mezey's group demonstrated that COX-2 is also involved in MSCs ability to suppress mast cell activation (Brown, Nemeth et al. 2011). Mast cells (MCs) have a key role in the induction of allergic inflammation and contribute to the severity of certain autoimmune diseases. An increasing body of literature also implicates MCs in the TME to affect tumor inflammation, angiogenesis, and growth (Ribatti, Nico et al. 2011). To date, few studies have investigated the potential of mast cell-MSC interactions. Since MCs are critical effector cells in allergic inflammation and they represent an important cell type to therapeutically target using the immune modulatory properties of MSCs, Mezey's group set out to study murine MC-MSCs effects. They reported that MSCs effectively suppressed specific MC functions in vitro and in animal models. MCs co-cultured with MSCs in direct contact, had dampened MC degranulation, pro-inflammatory cytokine production, chemokinesis, and chemotaxis. They also found that MC degranulation within mouse skin or the peritoneal cavity was suppressed following delivery of MSCs. Lastly, they discovered that these inhibitory effects were dependent on COX2 in MSCs (Brown, Nemeth et al. 2011).

Transforming growth factor- $\beta$ (TGF $\beta$ ) is an anti-inflammatory cytokine that is constitutively expressed by MSCs. The immune modulatory function of MSCs on T cells and natural killer cells can be impaired by treatment with neutralizing antibodies to TGF $\beta$ (Di Nicola, CarloStella et al. 2002; Sotiropoulou, Perez et al. 2006). In contrast, several studies have also established that TGF $\beta$ had no effect on the immunosuppressive properties of MSCs (Tse, Pendleton et al. 2003; Xu, Zhang et al. 2007). These discrepancies are likely explained by differences in species or experimental conditions. The importance of TGF $\beta$ in MSC therapy was recently established in a mouse model of ragweed-induced asthma. Mezey's group again demonstrated this assertion with neutralizing antibodies and the use of MSCs derived from TGF $\beta$ knockout mice (Nemeth, Keane-Myers et al. 2010). Notably, the number of Tregs in this model was elevated by the MSC-therapy. However, the role of TGF $\beta$ in this process was not directly studied, as was done by Patel et al. who showed that in co-cultures of peripheral blood mononuclear cells (PBMCs) with MSCs, TGF $\beta$ produced by MSCs resulted in increased numbers of Tregs (Patel, Meyer et al. 2010).

Several other factors are associated with the potential anti-inflammatory properties of MSCs including HLA-G, hepatocyte growth factor (HGF), leukemia inhibitory factor (LIF), IL1 receptor antagonist (IL1RA), CCL2, galectin-3, galectin-1 and semaphorin-3A, most of which attenuate $\mathrm{T}$ lymphocyte activation and are highly expressed by MSCs (Di Nicola, CarloStella et al. 2002; Ortiz, Dutreil et al. 2007; Di Ianni, Del Papa et al. 2008; Kang, Kang et al. 2008; Nasef, Ashammakhi et al. 2008; Rafei, Hsieh et al. 2008; Lepelletier, Lecourt et al. 2009; Selmani, Naji et al. 2009; Sioud, Mobergslien et al. 2010; Volarevic, Al-Qahtani et al. 2010). A recently advanced culprit is TNF-a-induced protein 6 TNAIP6 or TSG-6 (Lee, Pulin et al. 
2009; Prockop and Youn Oh 2011). TSG-6 secretion is known to suppress inflammation through the inhibition of the inflammatory network of proteases primarily by increasing the inhibitory activity of inter-a-inhibitor, sequestration of hyaluronan fragments, and decreasing neutrophil infiltration into sites of inflammation. In a model of acute inflammation induced by myocardial infarction, TSG-6 knockdown in MSCs significantly reduced their anti-inflammatory therapeutic effect. The administration of recombinant TSG6 protein largely duplicated the therapeutic effects of the delivered MSCs on inflammatory responses and infarct size (Getting, Mahoney et al. 2002; Wisniewski and Vilcek 2004; Milner, Higman et al. 2006; Forteza, Casalino-Matsuda et al. 2007; Lee, Pulin et al. 2009). Together these results make TSG-6 an interesting new factor in the anti-inflammatory effects of MSCs.

\subsubsection{Pro-inflammatory MSC responses}

Though we are beginning to better understand the many complex mechanisms associated with the secretion by MSCs of immune suppressive mediators like TSG-6, so far only a few reports have described a contrasting pro-inflammatory activity of MSCs that could be important in understanding the distinct role of MSCs in tumors. Indeed, the observation of this distinct MSCs immune effect came from studies primarily focused on the downstream consequences of TLR stimulation within these cells. TLRs are a conserved family of receptors that recognize pathogen- associated molecular patterns (PAMPs) and promote the activation of immune cells (Wright 1999-76; Triantafilou, Triantafilou et al. 2001; Sabroe, Read et al. 2003; Anders, Banas et al. 2004; Miggin and O'Neill 2006; West, Koblansky et al. 2006; Bunnell, Betancourt et al. 2010). Many TLRs (TLR1 to TLR13) have been identified and characterized in a variety of immune cell types and species. Agonists for TLRs include exogenous microbial components, such as LPS (TLR2 and 4), lipoproteins and peptidoglycans (TLR1, 2, 6), viral RNA (TLR3), bacterial and viral unmethylated CpG-DNA (TLR9), and endogenous molecules shed following cell injury, including heat shock proteins and extracellular matrix molecules (Wright 1999-77; Triantafilou, Triantafilou et al. 2001; Sabroe, Read et al. 2003; Anders, Banas et al. 2004; Miggin and O'Neill 2006; West, Koblansky et al. 2006; Bunnell, Betancourt et al. 2010). Specific agonist engagement of TLRs leads to the expression of inflammatory cytokines or co-stimulatory molecules by a MyD88 (a TLR adapter protein)-dependent or MyD88-independent signaling pathways and can promote chemotaxis of the stimulated cell. TLRs are differentially expressed on leukocyte subsets and non-immune cells and may regulate important aspects of innate and adaptive immune responses (Mempel, Voelcker et al. 2003; Hwa Cho, Bae et al. 2006; Nagai, Garrett et al. 2006; Pevsner-Fischer, Morad et al. 2006; West, Koblansky et al. 2006; Tomchuck, Zwezdaryk et al. 2008).

MSCs are among the cells that express an array of TLRs, including TLR2, 3, 4, 5, 6 and 9 (Hwa Cho, Bae et al. 2006; Pevsner-Fischer, Morad et al. 2006; Tomchuck, Zwezdaryk et al. 2008). Furthermore, studies by our group established that the stimulation of MSCs with TLR agonists led to the activation of downstream signaling pathways, including NF-kB, AKT, and mitogen-activated protein kinase (MAPK). Consequently, activation of these pathways triggers the previously unreported induction and secretion of pro-inflammatory cytokines, chemokines, and related TLR gene products. Interestingly, the unique patterns of affected genes, cytokines, and chemokines measured identified the TLRs as potential players in the 
established MSC immune modulatory properties, as well as their ability to migrate towards injured tissues. Surprisingly, we noted that TLR4 stimulation with LPS led to the secretion of primarily pro-inflammatory mediators, such as IL-1 $\beta$ and IL6 (Tomchuck, Zwezdaryk et al. 2008). Though unexpected, previous observations reported by Beyth et al. recognized that LPS priming affected co-cultures of leukocytes with human MSCs and attenuated the expected human MSC- mediated inhibition of T-lymphocyte activation as well as affected their capacity to secrete interferon (Beyth, Borovsky et al. 2005). More recently, RomieuMourez et al. showed that TLR stimulation in murine MSCs similarly resulted in the production of inflammatory mediators, such as IL-1, IL-6, IL-8, and CCL5 (Romieu-Mourez, Francois et al. 2009). Furthermore, they demonstrated that TLR and IFN activated murine MSCs injected within Matrigel matrices into mice resulted in the formation of an inflammatory site attracting innate immune cells and resulting in a dramatic recruitment of neutrophils. Raicevic et al., studying the effect of TLR activation within MSCs in an inflammatory milieu, observed that this environment shifted the cytokine profile to a proinflammatory one rather than the expected immunosuppressive one (Raicevic, Rouas et al. 2010). They similarly observed an increase in IL-1 $\beta$, IL-6, and IL-12 after TLR activation in this inflammatory context.

Though somewhat confounding, this recent body of work on the downstream consequences of TLRs provides emerging evidence for a new pro-inflammatory immune modulating role for MSCs. The identification of the molecular details for this new pro-inflammatory MSC role, and whether it is innate or just an in vitro artifact, awaits further investigation. However, this novel observation is important to consider given the accelerated use of MSCs in anti-inflammatory cell-based therapies. Additionally, as Raicevic et al. suggest targeting of TLRs in MSCs, may avoid deleterious consequences in their use as anti-inflammatory therapies (Raicevic, Rouas et al. 2010). By contrast, TLR-activated pro-inflammatory MSCs could prove useful in breaking tolerance in the therapy of immune evasive diseases, such as cancer.

\section{New MSC paradigm: Pro-inflammatory MSC1 and anti-inflammatory MSC2}

Our recent studies are partly an attempt to resolve some of the controversy surrounding the potential of MSCs to be anti-inflammatory in some cases and pro-inflammatory in others or to be pro-tumor in some cancers and anti-tumor in others, as described above. These studies led us to propose a new paradigm for MSCs based on the premise that these heterogeneous cells can be induced to polarize into two distinct but homogeneously acting phenotypes-that we modeled after monocytes, the other heterogeneous bone marrow-derived cells (Figure 2. Verreck, de Boer et al. 2006).

It is established that stimulation of monocytes with known cytokines or agonists to their TLRs, including IFN- $\gamma$ and endotoxin (LPS, TLR4-agonist), polarizes them into a classical M1 phenotype that participates in early pro-inflammatory responses. IL-4 treatment of monocytes yields the alternative M2 phenotype that is associated with anti-inflammatory resolution responses (Verreck, de Boer et al. 2006). We proposed that MSCs, like monocytes, are polarized by downstream TLR signaling into two homogenously acting phenotypes, classified as MSC1 and MSC2, following the monocyte nomenclature. We reported that TLR4 agonists polarized MSCs toward a pro-inflammatory MSC1 phenotype while the downstream consequences of TLR3 stimulation of MSCs was a skewing toward an antiinflammatory MSC2 phenotype. This novel MSC polarization paradigm is based on the 
consistent but novel outcomes observed for MSC1 when compared with MSC2 for several parameters, including dissimilar patterns of secretion of cytokines and chemokines and differences in differentiation capabilities, extracellular matrix deposition, TGF- $\beta$ signaling pathways, and Jagged, IDO and PGE-2 expression (Waterman, Tomchuck et al. 2010). The most compelling outcome was opposite effects of each cell type on T-lymphocyte activation (Waterman, Tomchuck et al. 2010).

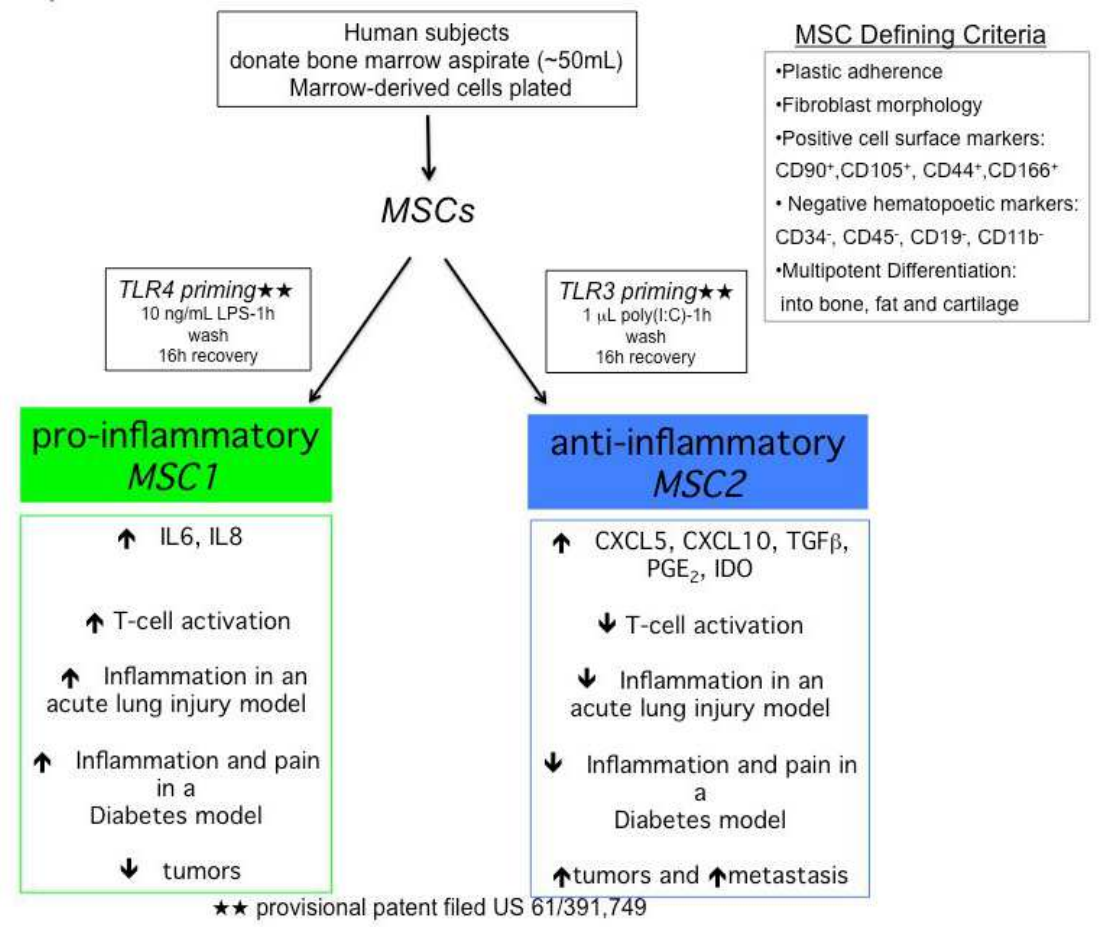

Fig. 2. Characteristics of the MSC1 and MSC2 Phenotypes. Short-term and low-level priming of TLR4 (left side) and TLR3 (right side) leads to the induction of heterogeneous hMSC preparations into a pro-inflammatory $M S C 1$ phenotype or an anti-inflammatory MSC2 phenotype. (adapted from (Tomchuck, Zwezdaryk et al. 2008; Waterman, Tomchuck et al. 2010)).

\subsection{Evidence for MSC1 and MSC2}

Our previous work, as well as that of others, established that MSCs reside in TMEs or tumor stroma, provide structural support for the malignant cells, modulate the tumor microenvironment, and consequently promote tumor growth and spread. Therefore, genemodified MSCs that can act as "Trojan horses" and deliver anti-cancer therapeutics into the tumor stroma are being evaluated as a promising new specific cell-based therapy for cancer. We also previously established that MSCs recruited to ovarian tumors by elevated secretion of LL-37 play a supportive role in ovarian tumor stroma. We found that specific induction of MSCs into MSC1 causes the secretion of pro-inflammatory mediators rather than anti- 
inflammatory ones, as well as promotes collagen rather than fibronectin deposition into the extracellular matrix (Figure 1)(Waterman, Tomchuck et al. 2010). Our preliminary studies support the notion that MSC1 may be effective in new cell-based treatment of cancers. Indeed, ovarian cancer cell lines co-cultured with MSC1 formed smaller tumor spheroids and had markedly reduced tumor colony forming potential; whereas, co-cultures with MSC2 phenotype had the expected pro-tumor effect. Moreover, MSC1-treated ovarian cancer cells were less invasive than MSC2-treated ones in matrigel coated transwell migration assays. Pilot tests in murine ovarian cancer models were consistent with these findings. MSC1 delivered in mice with established tumors had attenuated growth and spread. Mice treated with MSC2 had larger and more metastatic tumors.

MSC1 and MSC2 therapy has been successfully tested in several animal disease models and has resulted in predictable inflammatory responses and distinct effects on tumor growth and spread (Table 5).

\begin{tabular}{|c|c|c|c|c|c|c|}
\hline Animal Disease Model & $\begin{array}{c}\text { MSC-based } \\
\text { Therapy }\end{array}$ & $\begin{array}{l}\text { MSC } \\
\text { Dose } \\
\text { (cells) }\end{array}$ & $\begin{array}{c}\text { Treatment } \\
\text { Frequency } \\
\text { (Time of treatment) }\end{array}$ & $\begin{array}{l}\text { Disease } \\
\text { Impact }\end{array}$ & $\begin{array}{l}\text { Length of } \\
\text { study }\end{array}$ & $\begin{array}{l}\text { Adverse } \\
\text { Effects }\end{array}$ \\
\hline \multirow{3}{*}{$\begin{array}{l}\text { 1. LPS-induced } \\
\text { Acute Lung Injury (ALI) } \\
\text { (BalbC and C57BL/6J, } \\
n=12)\end{array}$} & MSCs & $0.5 \times 10^{6}$ & $1 \mathrm{X}$ (24hrs post-disease onset) & $\begin{array}{l}\text { Mostly anti- } \\
\text { inflammatory }\end{array}$ & \begin{tabular}{|l|}
1 week \\
post- \\
treatment
\end{tabular} & NONE \\
\hline & MSC1 & $0.5 \times 10^{\circ}$ & 1X (24hrs post-disease onset) & $\begin{array}{l}\text { Pro- } \\
\text { inflammatory }\end{array}$ & $\begin{array}{l}1 \text { week } \\
\text { post- } \\
\text { treatment }\end{array}$ & NONE \\
\hline & MSC2 & $0.5 \times 10^{6}$ & $1 \mathrm{X}$ (24hrs post-disease onset) & $\begin{array}{l}\text { Anti- } \\
\text { inflammatory }\end{array}$ & \begin{tabular}{|l|}
1 week \\
post- \\
treatment
\end{tabular} & NONE \\
\hline \multirow[t]{3}{*}{$\begin{array}{l}\text { 2. Streptozotocin-Induced } \\
\text { Diabetes and neuropathic } \\
\text { pain (C57BL/6J, } n=30)\end{array}$} & MSC's & $1-3 \times 10^{6}$ & $\begin{array}{l}3 \mathrm{X} \text { (given in 10-day intervals post- } \\
\text { disease onset) }\end{array}$ & $\begin{array}{l}\text { Mostly anti- } \\
\text { inflammatory }\end{array}$ & \begin{tabular}{|l|}
70 days \\
post- \\
treatment
\end{tabular} & NONE \\
\hline & MSC1 & $1-3 \times 10^{6}$ & $\begin{array}{l}3 \mathrm{X} \text { (given in 10-day intervals post- } \\
\text { disease onset) }\end{array}$ & $\begin{array}{l}\text { Pro- } \\
\text { inflammatory }\end{array}$ & \begin{tabular}{|l|}
70 days \\
post- \\
treatment
\end{tabular} & NONE \\
\hline & $M S C 2$ & $1-3 \times 10^{6}$ & $\begin{array}{l}3 \mathrm{X} \text { (given in 10-day intervals post- } \\
\text { disease onset) }\end{array}$ & $\begin{array}{l}\text { Anti- } \\
\text { inflammatory }\end{array}$ & $\begin{array}{l}70 \text { days } \\
\text { post- } \\
\text { treatment }\end{array}$ & NONE \\
\hline \multirow[t]{3}{*}{$\begin{array}{l}\text { 3. Immune-incompetent } \\
\text { human tumor xenografts } \\
\text { (Balb scid and nude } n=60 \text { ) }\end{array}$} & MSCs & $0.5 \times 10^{6}$ & $\begin{array}{l}3 \mathrm{X} \text { (given weekly post-disease } \\
\text { onset) }\end{array}$ & $\begin{array}{l}\text { Mostly anti- } \\
\text { inflammatory }\end{array}$ & $\begin{array}{l}>120 \text { days } \\
\text { post- } \\
\text { treatment }\end{array}$ & NONE \\
\hline & MSC1 & $0.5 \times 10^{6}$ & $\begin{array}{l}3 \mathrm{X} \text { (given weekly post-disease } \\
\text { onset) }\end{array}$ & $\begin{array}{l}\text { Pro- } \\
\text { inflammatory }\end{array}$ & \begin{tabular}{|l|}
$>120$ days \\
post- \\
treatment \\
\end{tabular} & NONE \\
\hline & MSC2 & $0.5 \times 10^{0}$ & $\begin{array}{l}3 \mathrm{X} \text { (given weekly post-disease } \\
\text { onset) }\end{array}$ & $\begin{array}{l}\text { Anti- } \\
\text { inflammatory }\end{array}$ & $\begin{array}{l}>120 \text { days } \\
\text { post- } \\
\text { treatment }\end{array}$ & NONE \\
\hline \multirow[t]{2}{*}{$\begin{array}{l}\text { 4. Immune-competent } \\
\operatorname{MOSEC}(\mathrm{C} 57 / \mathrm{BL} 6 \mathrm{~J} n=20)\end{array}$} & MSCs & $0.5 \times 10^{0}$ & $\begin{array}{l}3 \mathrm{X} \text { (given weekly post-disease } \\
\text { onset) }\end{array}$ & $\begin{array}{l}\text { Mostly anti- } \\
\text { inflammatory }\end{array}$ & \begin{tabular}{|l|}
$>70$ days \\
post- \\
treatment
\end{tabular} & NONE \\
\hline & MSC1 & $0.5 \times 10^{6}$ & $\begin{array}{l}3 \mathrm{X} \text { (given weekly post-disease } \\
\text { onset) }\end{array}$ & $\begin{array}{l}\text { Pro- } \\
\text { inflammatory }\end{array}$ & \begin{tabular}{|l|}
$>70$ days \\
post- \\
treatment
\end{tabular} & NONE \\
\hline
\end{tabular}

Table 5. Human MSC-based therapy of murine disease models.

Please NOTE that for all of the data presented MSCs represent conventionally prepared human MSCs, MSC1 are defined as the hMSCs incubated for $1 \mathrm{hr}$ with $10 \mathrm{ng} / \mathrm{mL}$ LPS and washed prior to delivery. MSC2 are defined as the hMSCs incubated for $1 \mathrm{hr}$ with $1 \mathrm{mg} / \mathrm{mL}$ poly(I:C) and washed prior to delivery (provisional patent filed US 61/391,749). 
Cancer models: Pilot studies with the mouse ovarian cancer model (MOSEC) and with a xenograft model demonstrate our assertions. A single delivery of MSC1-based therapy resulted in slower growing tumors, whereas comparable therapy with MSCs or MSC2 resulted in larger tumors and metastasis at the end of the study (day 65, Figure 3).

\section{MSC1 do not support tumor growth whereas MSC2 favor tumor growth and metastasis}
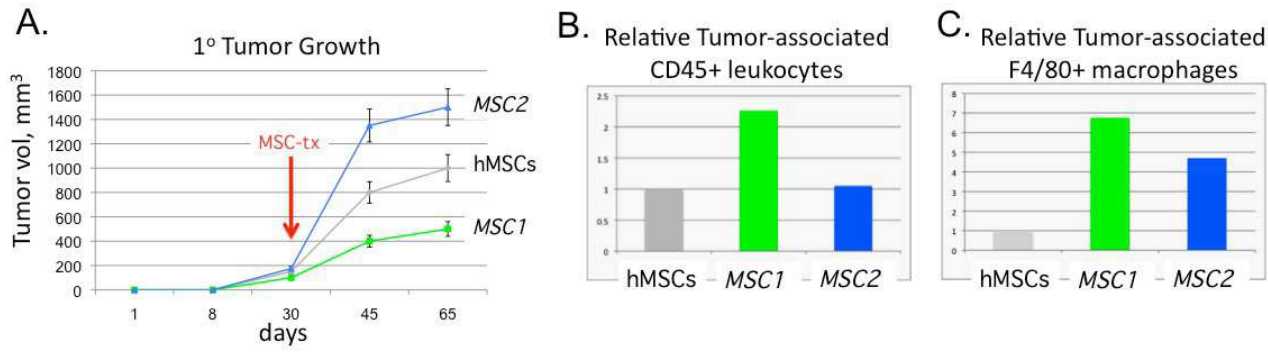

Fig. 3. MSC1 do not support tumor growth whereas MSC2 favor tumor growth and metastasis. The data show differences in tumor volume, CD45+leukocyte, and F4/80+ macrophage recruitment after the treatment of mice with established ovarian tumors, with human MSC1- and MSC2-based therapies. Methods The established syngeneic mouse model for epithelial ovarian cancer used is based upon a spontaneously transformed mouse ovarian surface epithelial cell (MOSEC) line ID8 that has been previously described (Roby, Taylor et al. 2000). 4-6 week-old female mice ( $n>10$ mice/MSC-treatment) were injected subcutaneously (s.c.) in the right hind leg with 1 X107 MOSEC cells. At approximately 4 weeks a single dose of labeled human MSCs (hMSCs), MSC1, or MSC2 (1X106/per mouse) were injected intraperitonealy (IP) as indicated by red arrow $\downarrow$. (A.) Tumor growth was measured with callipers as standard at weekly intervals until day of mouse sacrifice (Day 65). Harvested tumors and metastasis were weighed, counted and processed for flow cytometry and immunohistochemical analysis (IHC, Coffelt et al., 2009). Metastasis was found only in MSC2-treated mice (data not shown). MSCs were detected by flow cytometry and IHC. All MSC-treated samples had similar detectable MSCs within the tumor tissuetrending towards more MSC1 and MSC2 measured than hMSCs: approximately 15-25 cells counted per 200X field after 24hr of MSC-treatment and 2-5 cells at time of tissue harvest (day 65, data not shown). Sectioned tumor sample slides were stained with murine CD45 (B.) or F4/80 (C.) antibodies and the number of positively stained immune cells per 200X field were scored as described previously (Coffelt et al., 2009). Data are expressed as average cells counted in 4 fields/slide relative to hMSC sample. Data indicate in vivo stability and predictably distinct effects by the MSC1 and MSC2.

ALI model: In an established endotoxin-induced acute lung injury (ALI) mouse model, LPS, or endotoxin $(0.1 \mathrm{mg} / \mathrm{kg})$ was instilled intratracheally into adult Balb/C mice. After $24 \mathrm{hrs,}$ mice were each treated with $0.5 \times 10^{6}$ MSCs, MSC1, MSC2, or HBSS vehicle. To characterize inflammation, the lungs of the animals were lavaged and bronchioalveolar lavage fluid (BALF) was analyzed after $24 \mathrm{hr}$ for changes in neutrophil/monocyte recruitment (myeloperoxidase activity), total cell content by flow cytometry, and lung integrity by total protein leaked into the BALF $(n=12)$. MSC1-therapy aggravated the disease and resulted in 
increased neutrophil recruitment and more compromised lungs than the conventional MSC or MSC2 therapy.

Diabetes Model: Streptozotocin (STZ)-induced diabetic mice were procured from Jackson Laboratory (Bar Harbor, Maine). Blood glucose levels and animal weights were measured by standard methods. A month post STZ-injection, mice received intraperitonealy (IP) $0.5 \times 10^{6}$ cells of MSCs, MSC1, MSC2, or HBSS vehicle for a total of 3 times in 10-day intervals. Established behavioral assays to evaluate hyperalgesia and allodynia were conducted one day prior to each MSC therapy, as well as prior to sacrifice. Inflammatory factors and immune cell changes were measured as before to characterize the treatment effects on inflammation $(n=30)$. Again, all indicators were consistent with enhanced inflammation by MSC1-treatment and an improvement of disease by the MSC2- or MSC-treated animals. Manuscript in preparation.

Additionally in vitro studies show divergent effects of MSC1 and MSC2 on cancer cells. Coculture of various human cancer cell lines with MSC1 and MSC2 in Colony Forming Units (CFU) assays and 3-D tumor spheroid assays agree with the in vivo tumor models with different MSC1 and MSC2 treatment effects (Figure 4).

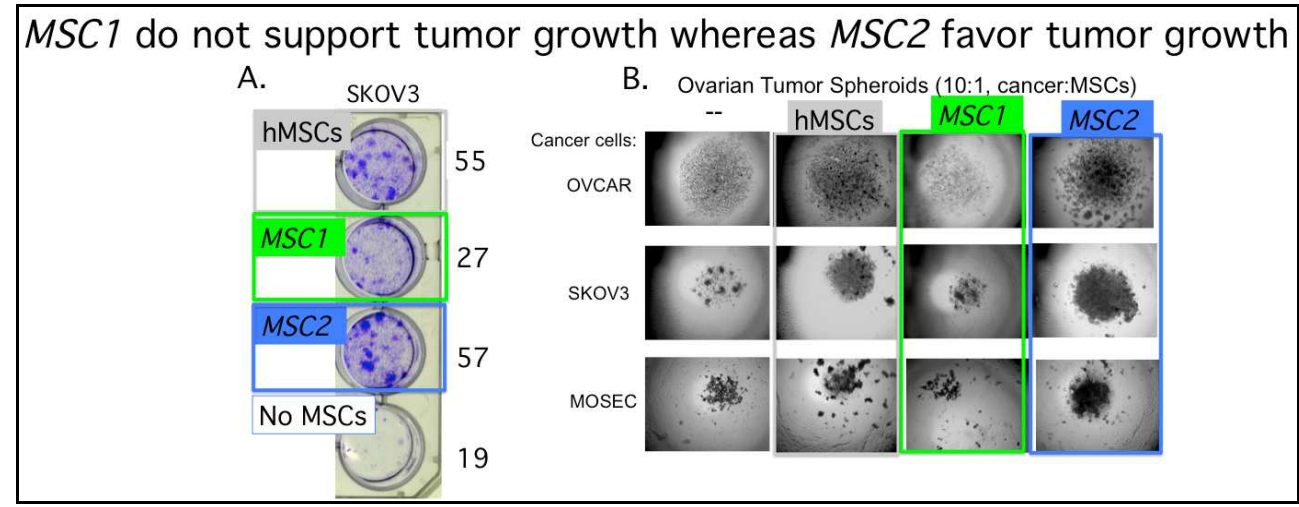

Fig. 4. MSC1 do not support tumor growth whereas MSC2 favor tumor growth: A. Data demonstrates that there are distinct effects on colony forming units (CFU) after coculture of different human cancer cell lines with untreated MSCs (hMSCs), MSC1, or MSC2. Methods: CFU assay was performed by culturing human tumor cells (200 cells/well) mixed with hMSCs, MSC1, or MSC2 (2 cells/well) at a ratio of 10 cancer cells per 1 MSC and plated in 24-well plates in growth medium supplemented with $10 \%$ FBS as indicated in figure. Cultures were grown for 14 days at $37^{\circ} \mathrm{C}$ in a humidified atmosphere of $5 \%$ carbon dioxide balance air. Growth medium was changed every 3-4 days. Colonies were visualized by staining with a crystal violet solution $(0.5 \%$ crystal violet $/ 10 \%$ ethanol). The resulting colonies were enumerated by the colony counting macro in ImageJ software, SKOV3ovarian cancer cell lines. Micrographs of the stained plates are shown. Colony counts are at right. $(n=8)$ B. Data demonstrates that there are distinct effects on tumor spheroids after coculture of different cancer cell lines with unprimed MSCs, MSC1, or MSC2. Methods: Tumor spheroids were formed by culturing tumor cells (2000 cells/well) mixed without any other cells (--) or with hMSCs, MSC1, or MSC2 (20 cells/well) at a ratio of 10 cancer cells per 
1 MSC and plated over 1.5\% agarose in 96-well plates in growth medium supplemented with $10 \%$ FBS as indicated in figure. Cultures were grown for 14 days at $37^{\circ} \mathrm{C}$ in a humidified atmosphere of $5 \%$ carbon dioxide balance air. Growth medium was changed every 3-4 days. Micrographs shown represent 20X magnified field of the 96-well plate. Cancer cell lines used are: OVCAR-human ovarian cancer, SKOV3-human ovarian cancer cell lines, and MOSEC-murine ovarian surface epithelium carcinoma cells. Data indicate distinct effects by MSC1 and MSC2 on cancer cell growth and spread.

\section{Conclusion}

The unique pathology of individual tumors presents a huge problem for conventional mono-specific therapies. New approaches aiming at developing effective treatments against cancer include the use of MSC-based therapies. There are many features that make this new strategy attractive and feasible. First, MSC-based therapies are already in clinical use and thus far have not been associated with adverse effects. Second, MSCs can be easily expanded and stored without any impact to their capabilities - a phenomenom that has triggered the creation of many new biotech start-ups. Third, once delivered, MSCs preferentially home to tumors and affect tumor growth and spread. Fourth, MSCs from nonself (allogeneic) or autologous (self) hosts can be safely delivered since they do not elicit immunity. Lastly, pre-clinical studies have demonstrated efficacy with geneticallyengineered MSCs that carry anti-cancer therapeutics that reached the tumors and prevented their growth.

MSCs targeted to cancers are expected to contribute many soluble factors such as mitogens, extracellular matrix proteins, angiogenic and inflammatory factors, as well as exosomes with as yet poorly defined potentials, once resident in the TME. MSCs are also expected to affect tumor-associated leukocytes either directly by cell-cell contact or indirectly by the secretion of trophic factors. MSCs are known to affect the proliferation and differentiation of dendritic cells, monocytes/macrophages, B and T cells, NK cells, and even mast cells. There has been a great deal of debate in the field in trying to assert whether MSCs resident in the TME contribute to tumor growth and spread or prevent it, and if so, by what mechanisms. Many reasons have been advanced to explain the contradictory MSC role in cancer including the heterogeneity of MSC preparations, the age or health of the MSC donor, and the experimental model or condition, to name a few. Our group has suggested a new paradigm for MSCs that we believe will help resolve some of the conflicting issues. The induction of MSCs into uniform and consistently acting pro-inflammatory MSC1 or antiinflammatory MSC2 phenotypes should provide convenient experimental tools that dissect the potential pro- and anti-tumor contributions of MSCs. MSC-based therapies stand to revolutionize medicine with the myriad ways that they can be manipulated and guided to reach pathologic tissue sites such as tumors. The continued investigation of these cells will ensure safe and effective therapy of human disease.

\section{Acknowledgment}

This work was supported by the National Institutes of Health grant 1P20RR20152-01, Department of Defense OC073102 Concept Award and research support from the Tulane Cancer Center and the Center for Stem Cell Research and Regenerative Medicine. 


\section{References}

Abdi, R., P. Fiorina, et al. (2008). "Immunomodulation by mesenchymal stem cells: a potential therapeutic strategy for type 1 diabetes." Diabetes 57(7): 1759-67.

Aggarwal, S. and M. F. Pittenger (2005). "Human mesenchymal stem cells modulate allogeneic immune cell responses." Blood 105(4): 1815-22.

Anand, P. K. (2010). "Exosomal membrane molecules are potent immune response modulators." Commun Integr Biol 3(5): 405-8.

Anders, H. J., B. Banas, et al. (2004). "Signaling danger: toll-like receptors and their potential roles in kidney disease." J Am Soc Nephrol 15(4): 854-67.

Asari, S., S. Itakura, et al. (2009). "Mesenchymal stem cells suppress B-cell terminal differentiation." Exp Hematol 37(5): 604-15.

Bartosh, T. J., J. H. Ylostalo, et al. (2010). "Aggregation of human mesenchymal stromal cells (MSCs) into 3D spheroids enhances their antiinflammatory properties." Proc Natl Acad Sci U S A 107(31): 13724-9.

Beyth, S., Z. Borovsky, et al. (2005). "Human mesenchymal stem cells alter antigenpresenting cell maturation and induce T-cell unresponsiveness." Blood 105(5): 22149.

Block, G. J., S. Ohkouchi, et al. (2008). "Multipotent Stromal Cells (MSCs) are Activated to Reduce Apoptosis in Part by Upregulation and Secretion of Stanniocalcin-1 (STC1)." Stem Cells.

Block, G. J., S. Ohkouchi, et al. (2009). "Multipotent stromal cells are activated to reduce apoptosis in part by upregulation and secretion of stanniocalcin-1." Stem Cells 27(3): 670-81.

Brown, J. M., K. Nemeth, et al. (2011). "Bone marrow stromal cells inhibit mast cell function via a COX2-dependent mechanism." Clin Exp Allergy 41(4): 526-34.

Bruder, S. P., N. Jaiswal, et al. (1997). "Growth kinetics, self-renewal, and the osteogenic potential of purified human mesenchymal stem cells during extensive subcultivation and following cryopreservation." J Cell Biochem 64(2): 278-94.

Bunnell, B. A., A. M. Betancourt, et al. (2010). "New concepts on the immune modulation mediated by mesenchymal stem cells." Stem Cell Res Ther 1(5): 34.

Caplan, A. I. and J. E. Dennis (2006). "Mesenchymal stem cells as trophic mediators." J Cell Biochem.

Chairoungdua, A., D. L. Smith, et al. (2010). "Exosome release of beta-catenin: a novel mechanism that antagonizes Wnt signaling." J Cell Biol 190(6): 1079-91.

Chen, K., D. Wang, et al. (2010). "Human umbilical cord mesenchymal stem cells hUC-MSCs exert immunosuppressive activities through a PGE2-dependent mechanism." Clin Immunol 135(3): 448-58.

Chen, T. S., R. C. Lai, et al. (2010). "Mesenchymal stem cell secretes microparticles enriched in pre-microRNAs." Nucleic Acids Res 38(1): 215-24.

Cheng, L., A. V. Ramesh, et al. (2010). "Mouse models for cancer stem cell research." Toxicol Pathol 38(1): 62-71.

Cho, J. A., H. Park, et al. (2011). "Exosomes from ovarian cancer cells induce adipose tissuederived mesenchymal stem cells to acquire the physical and functional characteristics of tumor-supporting myofibroblasts." Gynecol Oncol.

Cho, J. A., H. Park, et al. (2011). "Exosomes from breast cancer cells can convert adipose tissue-derived mesenchymal stem cells into myofibroblast-like cells." Int J Oncol. 
Coffelt, S. B., F. C. Marini, et al. (2009). "The pro-inflammatory peptide LL-37 promotes ovarian tumor progression through recruitment of multipotent mesenchymal stromal cells." Proc Natl Acad Sci U S A 106(10): 3806-11.

Coffelt, S. B. and A. B. Scandurro (2008). "Tumors sound the alarmin(s)." Cancer Res 68(16): 6482-5.

Cousin, B., E. Ravet, et al. (2009). "Adult stromal cells derived from human adipose tissue provoke pancreatic cancer cell death both in vitro and in vivo." PLoS One 4(7): e6278.

da Silva Meirelles, L., A. I. Caplan, et al. (2008). "In search of the in vivo identity of mesenchymal stem cells." Stem Cells 26(9): 2287-99.

Danchuk, S., J. H. Ylostalo, et al. (2011). "Human multipotent stromal cells attenuate lipopolysaccharide-induced acute lung injury in mice via secretion of tumor necrosis factor-alpha-induced protein 6." Stem Cell Res Ther 2(3): 27.

Dasari, V. R., K. Kaur, et al. (2010). "Upregulation of PTEN in glioma cells by cord blood mesenchymal stem cells inhibits migration via downregulation of the PI3K/Akt pathway." PLoS One 5(4): e10350.

Dasari, V. R., K. K. Velpula, et al. (2010). "Cord blood stem cell-mediated induction of apoptosis in glioma downregulates X-linked inhibitor of apoptosis protein (XIAP)." PLoS One 5(7): e11813.

Di Ianni, M., B. Del Papa, et al. (2008). "Mesenchymal cells recruit and regulate T regulatory cells." Exp Hematol 36(3): 309-18.

Di Nicola, M., C. Carlo-Stella, et al. (2002). "Human bone marrow stromal cells suppress Tlymphocyte proliferation induced by cellular or nonspecific mitogenic stimuli." Blood 99(10): 3838-43.

Digirolamo, C. M., D. Stokes, et al. (1999). "Propagation and senescence of human marrow stromal cells in culture: a simple colony-forming assay identifies samples with the greatest potential to propagate and differentiate." Br J Haematol 107(2): 275-81.

Djouad, F., V. Fritz, et al. (2005). "Reversal of the immunosuppressive properties of mesenchymal stem cells by tumor necrosis factor alpha in collagen-induced arthritis." Arthritis Rheum 52(5): 1595-603.

Djouad, F., P. Plence, et al. (2003). "Immunosuppressive effect of mesenchymal stem cells favors tumor growth in allogeneic animals." Blood 102(10): 3837-44.

Duffy, M. M., J. Pindjakova, et al. (2011). "Mesenchymal stem cell inhibition of T-helper 17 differentiation is triggered by cell-cell contact and mediated by prostaglandin E2 via the EP4 receptor." Eur J Immunol.

Duffy, M. M., T. Ritter, et al. (2011). "Mesenchymal stem cell effects on T-cell effector pathways." Stem Cell Res Ther 2(4): 34.

Feng, J., A. Mantesso, et al. "Dual origin of mesenchymal stem cells contributing to organ growth and repair." Proc Natl Acad Sci U S A 108(16): 6503-8.

Fibbe, W. E., A. J. Nauta, et al. (2007). "Modulation of immune responses by mesenchymal stem cells." Ann N Y Acad Sci 1106: 272-8.

Forteza, R., S. M. Casalino-Matsuda, et al. (2007). "TSG-6 potentiates the antitissue kallikrein activity of inter-alpha-inhibitor through bikunin release." Am J Respir Cell Mol Biol 36(1): 20-31.

Frese, K. K. and D. A. Tuveson (2007). "Maximizing mouse cancer models." Nat Rev Cancer 7(9): 645-58. 
Friedenstein, A. J., S. Piatetzky, II, et al. (1966). "Osteogenesis in transplants of bone marrow cells." J Embryol Exp Morphol 16(3): 381-90.

Galie, M., G. Konstantinidou, et al. (2008). "Mesenchymal stem cells share molecular signature with mesenchymal tumor cells and favor early tumor growth in syngeneic mice." Oncogene 27(18): 2542-51.

Getting, S. J., D. J. Mahoney, et al. (2002). "The link module from human TSG-6 inhibits neutrophil migration in a hyaluronan- and inter-alpha -inhibitor-independent manner." J Biol Chem 277(52): 51068-76.

Giuliani, M., N. Oudrhiri, et al. (2011). "Human mesenchymal stem cells derived from induced pluripotent stem cells downregulate NK cell cytolytic machinery." Blood.

Gur-Wahnon, D., Z. Borovsky, et al. (2007). "Contact-dependent induction of regulatory antigen-presenting cells by human mesenchymal stem cells is mediated via STAT3 signaling." Exp Hematol 35(3): 426-33.

Gur-Wahnon, D., Z. Borovsky, et al. (2009). "The induction of APC with a distinct tolerogenic phenotype via contact-dependent STAT3 activation." PLoS One 4(8): e6846.

Hashimoto, J., Y. Kariya, et al. (2006). "Regulation of proliferation and chondrogenic differentiation of human mesenchymal stem cells by laminin-5 (laminin-332)." Stem Cells 24(11): 2346-54.

Hass, R., C. Kasper, et al. (2011). "Different populations and sources of human mesenchymal stem cells (MSC): A comparison of adult and neonatal tissue-derived MSC." Cell Commun Signal 9: 12.

Hwa Cho, H., Y. C. Bae, et al. (2006). "Role of Toll-Like Receptors on Human AdiposeDerived Stromal Cells." Stem Cells \%R 10.1634/stemcells.2006-0189 24(12): 2744-2752.

Jaiswal, N., S. E. Haynesworth, et al. (1997). "Osteogenic differentiation of purified, cultureexpanded human mesenchymal stem cells in vitro." J Cell Biochem 64(2): 295-312.

Ju, S., G. J. Teng, et al. (2010). "In vivo differentiation of magnetically labeled mesenchymal stem cells into hepatocytes for cell therapy to repair damaged liver." Invest Radiol 45(10): 625-33.

Kang, J. W., K. S. Kang, et al. (2008). "Soluble factors-mediated immunomodulatory effects of canine adipose tissue-derived mesenchymal stem cells." Stem Cells Dev 17(4): 68193.

Karnoub, A. E., A. B. Dash, et al. (2007). "Mesenchymal stem cells within tumour stroma promote breast cancer metastasis." Nature 449(7162): 557-63.

Khakoo, A. Y., S. Pati, et al. (2006). "Human mesenchymal stem cells exert potent antitumorigenic effects in a model of Kaposi's sarcoma." J Exp Med 203(5): 1235-47.

Kidd, S., E. Spaeth, et al. (2008). "The (in) auspicious role of mesenchymal stromal cells in cancer: be it friend or foe." Cytotherapy 10(7): 657-67.

Kim, J. and P. Hematti (2009). "Mesenchymal stem cell-educated macrophages: a novel type of alternatively activated macrophages." Exp Hematol 37(12): 1445-53.

Kim, S. M., J. Y. Lim, et al. (2008). "Gene therapy using TRAIL-secreting human umbilical cord blood-derived mesenchymal stem cells against intracranial glioma." Cancer Res 68(23): 9614-23.

Klopp, A. H., A. Gupta, et al. (2010). "Dissecting a Discrepancy in the Literature: Do Mesenchymal Stem Cells Support or Suppress Tumor Growth?" Stem Cells. 
Klopp, A. H., A. Gupta, et al. (2011). "Concise review: Dissecting a discrepancy in the literature: do mesenchymal stem cells support or suppress tumor growth?" Stem Cells 29(1): 11-9.

Koh, W., C. T. Sheng, et al. (2010). "Analysis of deep sequencing microRNA expression profile from human embryonic stem cells derived mesenchymal stem cells reveals possible role of let-7 microRNA family in downstream targeting of hepatic nuclear factor 4 alpha." BMC Genomics 11 Suppl 1: S6.

Kong, Q. F., B. Sun, et al. (2009). "BM stromal cells ameliorate experimental autoimmune myasthenia gravis by altering the balance of Th cells through the secretion of IDO." Eur J Immunol 39(3): 800-9.

Kopen, G. C., D. J. Prockop, et al. (1999). "Marrow stromal cells migrate throughout forebrain and cerebellum, and they differentiate into astrocytes after injection into neonatal mouse brains." Proc Natl Acad Sci U S A 96(19): 10711-6.

Krampera, M., L. Cosmi, et al. (2006). "Role for interferon-gamma in the immunomodulatory activity of human bone marrow mesenchymal stem cells." Stem Cells 24(2): 386-98.

Krampera, M., S. Glennie, et al. (2003). "Bone marrow mesenchymal stem cells inhibit the response of naive and memory antigen-specific $\mathrm{T}$ cells to their cognate peptide." Blood 101(9): 3722-9.

Krampera, M., A. Pasini, et al. (2006). "Regenerative and immunomodulatory potential of mesenchymal stem cells." Curr Opin Pharmacol 6(4): 435-41.

Kucerova, L., M. Matuskova, et al. "Tumor cell behaviour modulation by mesenchymal stromal cells." Mol Cancer 9: 129.

Lai, R. C., F. Arslan, et al. (2010). "Exosome secreted by MSC reduces myocardial ischemia/reperfusion injury." Stem Cell Res 4(3): 214-22.

Le Blanc, K., I. Rasmusson, et al. (2004). "Treatment of severe acute graft-versus-host disease with third party haploidentical mesenchymal stem cells." Lancet 363(9419): 1439-41.

Lee, R. H., A. A. Pulin, et al. (2009). "Intravenous hMSCs improve myocardial infarction in mice because cells embolized in lung are activated to secrete the anti-inflammatory protein TSG-6." Cell Stem Cell 5(1): 54-63.

Lepelletier, Y., S. Lecourt, et al. (2009). "Galectin-1 and semaphorin-3A are two soluble factors conferring T-cell immunosuppression to bone marrow mesenchymal stem cell." Stem Cells Dev 19(7): 1075-9.

Lin, G., R. Yang, et al. (2010). "Effects of transplantation of adipose tissue-derived stem cells on prostate tumor." Prostate 70(10): 1066-73.

Lopez Ponte, A., E. Marais, et al. (2007). "The in vitro migration capacity of human bone marrow mesenchymal stem cells: Comparison of chemokine and growth factor chemotactic activities." Stem Cells.

Lu, Y. R., Y. Yuan, et al. (2008). "The growth inhibitory effect of mesenchymal stem cells on tumor cells in vitro and in vivo." Cancer Biol Ther 7(2): 245-51.

Mader, E. K., Y. Maeyama, et al. (2009). "Mesenchymal stem cell carriers protect oncolytic measles viruses from antibody neutralization in an orthotopic ovarian cancer therapy model." Clin Cancer Res 15(23): 7246-55.

Maestroni, G. J., E. Hertens, et al. (1999). "Factor(s) from nonmacrophage bone marrow stromal cells inhibit Lewis lung carcinoma and B16 melanoma growth in mice." Cell Mol Life Sci 55(4): 663-7. 
Maggini, J., G. Mirkin, et al. (2010). "Mouse bone marrow-derived mesenchymal stromal cells turn activated macrophages into a regulatory-like profile." PLoS One 5(2): e9252.

Mantovani, A., A. Sica, et al. (2007). "New vistas on macrophage differentiation and activation." Eur J Immunol 37(1): 14-6.

Mantovani, A., S. Sozzani, et al. (2002). "Macrophage polarization: tumor-associated macrophages as a paradigm for polarized M2 mononuclear phagocytes." Trends Immunol 23(11): 549-55.

Martinez, F. O., S. Gordon, et al. (2006). "Transcriptional profiling of the human monocyteto-macrophage differentiation and polarization: new molecules and patterns of gene expression." J Immunol 177(10): 7303-11.

Meirelles Lda, S., A. M. Fontes, et al. (2009). "Mechanisms involved in the therapeutic properties of mesenchymal stem cells." Cytokine Growth Factor Rev 20(5-6): 419-27.

Mempel, M., V. Voelcker, et al. (2003). "Toll-like receptor expression in human keratinocytes: nuclear factor kappaB controlled gene activation by Staphylococcus aureus is tolllike receptor 2 but not toll-like receptor 4 or platelet activating factor receptor dependent." J Invest Dermatol 121(6): 1389-96.

Mezey, E., B. Mayer, et al. (2009). "Unexpected roles for bone marrow stromal cells (or MSCs): a real promise for cellular, but not replacement, therapy." Oral Dis.

Miggin, S. M. and L. A. O'Neill (2006). "New insights into the regulation of TLR signaling." J Leukoc Biol 80(2): 220-6.

Milner, C. M., V. A. Higman, et al. (2006). "TSG-6: a pluripotent inflammatory mediator?" Biochem Soc Trans 34(Pt 3): 446-50.

Mosser, D. M. and J. P. Edwards (2008). "Exploring the full spectrum of macrophage activation." Nat Rev Immunol 8(12): 958-69.

Mosser, D. M. and X. Zhang (2008). "Activation of murine macrophages." Curr Protoc Immunol Chapter 14: Unit 142.

Muehlberg, F. L., Y. H. Song, et al. (2009). "Tissue-resident stem cells promote breast cancer growth and metastasis." Carcinogenesis 30(4): 589-97.

Nagai, Y., K. P. Garrett, et al. (2006). "Toll-like receptors on hematopoietic progenitor cells stimulate innate immune system replenishment." Immunity 24(6): 801-12.

Najar, M., G. Raicevic, et al. "Mesenchymal stromal cells use PGE2 to modulate activation and proliferation of lymphocyte subsets: Combined comparison of adipose tissue, Wharton's Jelly and bone marrow sources." Cell Immunol 264(2): 171-9.

Nakamizo, A., F. Marini, et al. (2005). "Human bone marrow-derived mesenchymal stem cells in the treatment of gliomas." Cancer Res 65(8): 3307-18.

Nasef, A., N. Ashammakhi, et al. (2008). "Immunomodulatory effect of mesenchymal stromal cells: possible mechanisms." Regen Med 3(4): 531-46.

Nauta, A. J. and W. E. Fibbe (2007). "Immunomodulatory properties of mesenchymal stromal cells." Blood 110(10): 3499-506.

Nemeth, K., A. Keane-Myers, et al. (2010). "Bone marrow stromal cells use TGF-beta to suppress allergic responses in a mouse model of ragweed-induced asthma." Proc Natl Acad Sci U S A 107(12): 5652-7.

Nemeth, K., A. Leelahavanichkul, et al. (2009). "Bone marrow stromal cells attenuate sepsis via prostaglandin $\mathrm{E}(2)$-dependent reprogramming of host macrophages to increase their interleukin-10 production." Nat Med 15(1): 42-9. 
Nemeth, K., B. Mayer, et al. (2009). "Modulation of bone marrow stromal cell functions in infectious diseases by toll-like receptor ligands." J Mol Med.

Ohlsson, L. B., L. Varas, et al. (2003). "Mesenchymal progenitor cell-mediated inhibition of tumor growth in vivo and in vitro in gelatin matrix." Exp Mol Pathol 75(3): 248-55.

Opitz, C. A., U. M. Litzenburger, et al. (2009). "Toll-like receptor engagement enhances the immunosuppressive properties of human bone marrow-derived mesenchymal stem cells by inducing indoleamine-2,3-dioxygenase- 1 via interferon-beta and protein kinase R." Stem Cells 27(4): 909-19.

Ortiz, L. A., M. Dutreil, et al. (2007). "Interleukin 1 receptor antagonist mediates the antiinflammatory and antifibrotic effect of mesenchymal stem cells during lung injury." Proc Natl Acad Sci U S A 104(26): 11002-7.

Otsu, K., S. Das, et al. (2009). "Concentration-dependent inhibition of angiogenesis by mesenchymal stem cells." Blood 113(18): 4197-205.

Patel, S. A., J. R. Meyer, et al. (2010). "Mesenchymal stem cells protect breast cancer cells through regulatory $\mathrm{T}$ cells: role of mesenchymal stem cell-derived TGF-beta." $J$ Immunol 184(10): 5885-94.

Pevsner-Fischer, M., V. Morad, et al. (2006). "Toll-like receptors and their ligands control mesenchymal stem cell functions." Blood \%R 10.1182/blood-2006-06-028704: blood2006-06-028704.

Phinney, D. G., G. Kopen, et al. (1999). "Plastic adherent stromal cells from the bone marrow of commonly used strains of inbred mice: variations in yield, growth, and differentiation." J Cell Biochem 72(4): 570-85.

Phinney, D. G., G. Kopen, et al. (1999). "Donor variation in the growth properties and osteogenic potential of human marrow stromal cells." J Cell Biochem 75(3): 424-36.

Pittenger, M. F., A. M. Mackay, et al. (1999). "Multilineage potential of adult human mesenchymal stem cells." Science 284(5411): 143-7.

Prantl, L., F. Muehlberg, et al. "Adipose tissue-derived stem cells promote prostate tumor growth." Prostate 70(15): 1709-15.

Prasanna, S. J., D. Gopalakrishnan, et al. (2010). "Pro-inflammatory cytokines, IFNgamma and TNFalpha, influence immune properties of human bone marrow and Wharton jelly mesenchymal stem cells differentially." PLoS One 5(2): e9016.

Prockop, D. J. (2003). "Further proof of the plasticity of adult stem cells and their role in tissue repair." J Cell Biol 160(6): 807-9.

Prockop, D. J. (2009). "Repair of tissues by adult stem/progenitor cells (MSCs): controversies, myths, and changing paradigms." Mol Ther 17(6): 939-46.

Prockop, D. J. and J. Youn Oh (2011). "Mesenchymal Stem/Stromal Cells (MSCs): Role as Guardians of Inflammation." Mol Ther.

Qiao, L., Z. Xu, et al. (2008). "Suppression of tumorigenesis by human mesenchymal stem cells in a hepatoma model." Cell Res 18(4): 500-7.

Qiao, L., Z. L. Xu, et al. (2008). "Dkk-1 secreted by mesenchymal stem cells inhibits growth of breast cancer cells via depression of Wnt signalling." Cancer Lett 269(1): 67-77.

Rafei, M., J. Hsieh, et al. (2008). "Mesenchymal stromal cell-derived CCL2 suppresses plasma cell immunoglobulin production via STAT3 inactivation and PAX5 induction." Blood 112(13): 4991-8. 
Raicevic, G., R. Rouas, et al. (2010). "Inflammation modifies the pattern and the function of Toll-like receptors expressed by human mesenchymal stromal cells." Hum Immunol 71(3): 235-44.

Ramasamy, R., H. Fazekasova, et al. (2007). "Mesenchymal stem cells inhibit dendritic cell differentiation and function by preventing entry into the cell cycle." Transplantation 83(1): 71-6.

Ren, C., S. Kumar, et al. (2008). "Therapeutic potential of mesenchymal stem cells producing interferon-alpha in a mouse melanoma lung metastasis model." Stem Cells 26(9): 2332-8.

Ren, C., S. Kumar, et al. (2008). "Cancer gene therapy using mesenchymal stem cells expressing interferon-beta in a mouse prostate cancer lung metastasis model." Gene Ther 15(21): 1446-53.

Ren, G., T. Li, et al. (2007). "Lentiviral RNAi-induced downregulation of adenosine kinase in human mesenchymal stem cell grafts: a novel perspective for seizure control." Exp Neurol 208(1): 26-37.

Ren, G., L. Zhang, et al. (2008). "Mesenchymal stem cell-mediated immunosuppression occurs via concerted action of chemokines and nitric oxide." Cell Stem Cell 2(2): 14150.

Ribatti, D., B. Nico, et al. (2011). "Tryptase-positive mast cells and CD8-positive T cells in human endometrial cancer." Pathol Int 61(7): 442-4.

Roby, K. F., C. C. Taylor, et al. (2000). "Development of a syngeneic mouse model for events related to ovarian cancer." Carcinogenesis 21(4): 585-91.

Roddy, G. W., J. Y. Oh, et al. (2011). "Action at a Distance: Systemically Administered Adult Stem/Progenitor Cells (MSCs) Reduce Inflammatory Damage to the Cornea Without Engraftment and Primarily by Secretion of TSG-6." Stem Cells.

Romieu-Mourez, R., M. Francois, et al. (2009). "Cytokine modulation of TLR expression and activation in mesenchymal stromal cells leads to a proinflammatory phenotype." $J$ Immunol 182(12): 7963-73.

Ryan, J. M., F. Barry, et al. (2007). "Interferon-gamma does not break, but promotes the immunosuppressive capacity of adult human mesenchymal stem cells." Clin Exp Immunol 149(2): 353-63.

Sabroe, I., R. C. Read, et al. (2003). "Toll-like receptors in health and disease: complex questions remain." J Immunol 171(4): 1630-5.

Sakaguchi, Y., I. Sekiya, et al. (2005). "Comparison of human stem cells derived from various mesenchymal tissues: superiority of synovium as a cell source." Arthritis Rheum 52(8): 2521-9.

Salem, H. K. and C. Thiemermann (2010). "Mesenchymal stromal cells: current understanding and clinical status." Stem Cells 28(3): 585-96.

Secchiero, P., S. Zorzet, et al. (2010). "Human bone marrow mesenchymal stem cells display anti-cancer activity in SCID mice bearing disseminated non-Hodgkin's lymphoma xenografts." PLoS One 5(6): e11140.

Selmani, Z., A. Naji, et al. (2009). "HLA-G is a crucial immunosuppressive molecule secreted by adult human mesenchymal stem cells." Transplantation 87(9 Suppl): S62-6.

Shi, C., T. Jia, et al. (2011). "Bone marrow mesenchymal stem and progenitor cells induce monocyte emigration in response to circulating toll-like receptor ligands." Immunity 34(4): 590-601. 
Shinagawa, K., Y. Kitadai, et al. "Mesenchymal stem cells enhance growth and metastasis of colon cancer." Int J Cancer 127(10): 2323-33.

Singer, N. G. and A. I. Caplan (2011). "Mesenchymal stem cells: mechanisms of inflammation." Annu Rev Pathol 6: 457-78.

Sioud, M., A. Mobergslien, et al. (2010). "Evidence for the involvement of galectin-3 in mesenchymal stem cell suppression of allogeneic T-cell proliferation." Scand J Immunol 71(4): 267-74.

Sotiropoulou, P. A., S. A. Perez, et al. (2006). "Interactions between human mesenchymal stem cells and natural killer cells." Stem Cells 24(1): 74-85.

Studeny, M., F. C. Marini, et al. (2002). "Bone marrow-derived mesenchymal stem cells as vehicles for interferon-beta delivery into tumors." Cancer Res 62(13): 3603-8.

Studeny, M., F. C. Marini, et al. (2004). "Mesenchymal stem cells: potential precursors for tumor stroma and targeted-delivery vehicles for anticancer agents." J Natl Cancer Inst 96(21): 1593-603.

Sun, Y., L. Chen, et al. (2007). "Differentiation of bone marrow-derived mesenchymal stem cells from diabetic patients into insulin-producing cells in vitro." Chin Med J (Engl) 120(9): 771-6.

Sze, S. K., D. P. de Kleijn, et al. (2007). "Elucidating the secretion proteome of human embryonic stem cell-derived mesenchymal stem cells." Mol Cell Proteomics 6(10): 1680-9.

Tan, A., H. De La Pena, et al. (2010). "The application of exosomes as a nanoscale cancer vaccine." Int J Nanomedicine 5: 889-900.

Tolar, J., K. Le Blanc, et al. (2010). "Concise review: hitting the right spot with mesenchymal stromal cells." Stem Cells 28(8): 1446-55.

Tomchuck, S. L., K. J. Zwezdaryk, et al. (2008). "Toll-like receptors on human mesenchymal stem cells drive their migration and immunomodulating responses." Stem Cells 26(1): 99-107.

Triantafilou, K., M. Triantafilou, et al. (2001). "A CD14-independent LPS receptor cluster." Nat Immunol 2(4): 338-45.

Tse, W. T., J. D. Pendleton, et al. (2003). "Suppression of allogeneic T-cell proliferation by human marrow stromal cells: implications in transplantation." Transplantation 75(3): 389-97.

Uccelli, A., L. Moretta, et al. (2008). "Mesenchymal stem cells in health and disease." Nat Rev Immunol 8(9): 726-36.

Verreck, F. A., T. de Boer, et al. (2006). "Phenotypic and functional profiling of human proinflammatory type- 1 and anti-inflammatory type- 2 macrophages in response to microbial antigens and IFN-gamma- and CD40L-mediated costimulation." J Leukoc Biol 79(2): 285-93.

Volarevic, V., A. Al-Qahtani, et al. (2010). "Interleukin-1 receptor antagonist (IL-1Ra) and IL$1 \mathrm{Ra}$ producing mesenchymal stem cells as modulators of diabetogenesis." Autoimmunity 43(4): 255-63.

Waterman, R. S., S. L. Tomchuck, et al. (2010). "A new mesenchymal stem cell (MSC) paradigm: polarization into a pro-inflammatory MSC1 or an Immunosuppressive MSC2 phenotype." PLoS One 5(4): e10088. 
Waterman R.S. and Betancourt A.M. (2011). "Distinct Roles for Mesenchymal Stem Cell Phenotypes: MSC1 and MSC2 in Tumors." Cancer Research Manuscript in Preparation.

Webber, J., R. Steadman, et al. (2010). "Cancer exosomes trigger fibroblast to myofibroblast differentiation." Cancer Res 70(23): 9621-30.

Weiss, D. J., I. Bertoncello, et al. (2011). "Stem cells and cell therapies in lung biology and lung diseases." Proc Am Thorac Soc 8(3): 223-72.

West, A. P., A. A. Koblansky, et al. (2006). "Recognition and signaling by toll-like receptors." Annu Rev Cell Dev Biol 22: 409-37.

Wisniewski, H. G. and J. Vilcek (2004). "Cytokine-induced gene expression at the crossroads of innate immunity, inflammation and fertility: TSG-6 and PTX3/TSG-14." Cytokine Growth Factor Rev 15(2-3): 129-46.

Wright, S. D. (1999). "Toll, a new piece in the puzzle of innate immunity." J Exp Med 189(4): 605-9.

$\mathrm{Xu}, \mathrm{G} ., \mathrm{L}$. Zhang, et al. (2007). "Immunosuppressive properties of cloned bone marrow mesenchymal stem cells." Cell Res 17(3): 240-8.

Yu, Y., H. Ren, et al. (2008). "[Differentiation of human umbilical cord blood-derived mesenchymal stem cells into chondroblast and osteoblasts]." Sheng Wu Yi Xue Gong Cheng Xue Za Zhi 25(6): 1385-9.

Zhang, Q. Z., W. R. Su, et al. (2010). "Human gingiva-derived mesenchymal stem cells elicit polarization of $\mathrm{m} 2$ macrophages and enhance cutaneous wound healing." Stem Cells 28(10): 1856-68.

Zhu, W., W. Xu, et al. (2006). "Mesenchymal stem cells derived from bone marrow favor tumor cell growth in vivo." Exp Mol Pathol 80(3): 267-74.

Zhu, Y., Z. Sun, et al. (2009). "Human mesenchymal stem cells inhibit cancer cell proliferation by secreting DKK-1." Leukemia 23(5): 925-33.

Zuckerman, K. S. and M. S. Wicha (1983). "Extracellular matrix production by the adherent cells of long-term murine bone marrow cultures." Blood 61(3): 540-7.

Zwezdaryk, K. J., S. B. Coffelt, et al. (2007). "Erythropoietin, a hypoxia-regulated factor, elicits a pro-angiogenic program in human mesenchymal stem cells." Exp Hematol 35(4): 640-52. 


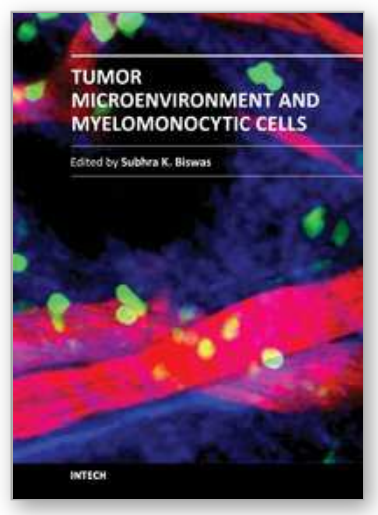

\author{
Tumor Microenvironment and Myelomonocytic Cells \\ Edited by Dr. Subhra Biswas
}

ISBN 978-953-51-0439-1

Hard cover, 298 pages

Publisher InTech

Published online 30, March, 2012

Published in print edition March, 2012

Tumor microenvironment represents an extremely dynamic niche shaped by the interplay of different cell types (e.g. tumor cells, stromal cells), their soluble products (e.g.cytokines, chemokines and growth factors) and varied physico-chemical conditions (e.g low oxygen concentration or hypoxia). Recent studies have identified myelomonocytic cells as key players in regulating the tumor microenvironment and hence, tumor progression in a variety of cancers. In view of these findings, the present book attemps to provide a comprehensive account of the diversity of tumor microenvironment across different cancers and how myelomonocytic cells have taken the center-stage in regulating this niche to direct cancer progression. A better understanding of the myelomonocytic cells and the mechanisms by which they regulate cancer progression will open new vistas in cancer therapeutics.

\title{
How to reference
}

In order to correctly reference this scholarly work, feel free to copy and paste the following:

Aline M. Betancourt and Ruth S. Waterman (2012). The Role of Mesenchymal Stem Cells in the Tumor Microenvironment, Tumor Microenvironment and Myelomonocytic Cells, Dr. Subhra Biswas (Ed.), ISBN: 978953-51-0439-1, InTech, Available from: http://www.intechopen.com/books/tumor-microenvironment-andmyelomonocytic-cells/the-role-of-mesenchymal-stem-cells-in-the-tumor-microenvironment

\section{INTECH}

open science | open minds

\author{
InTech Europe \\ University Campus STeP Ri \\ Slavka Krautzeka 83/A \\ 51000 Rijeka, Croatia \\ Phone: +385 (51) 770447 \\ Fax: +385 (51) 686166 \\ www.intechopen.com
}

\author{
InTech China \\ Unit 405, Office Block, Hotel Equatorial Shanghai \\ No.65, Yan An Road (West), Shanghai, 200040, China \\ 中国上海市延安西路65号上海国际贵都大饭店办公楼 405 单元 \\ Phone: +86-21-62489820 \\ Fax: +86-21-62489821
}


(C) 2012 The Author(s). Licensee IntechOpen. This is an open access article distributed under the terms of the Creative Commons Attribution 3.0 License, which permits unrestricted use, distribution, and reproduction in any medium, provided the original work is properly cited. 